\title{
VALUATION OF REVERSE MORTGAGE WITH DEPENDENT JOINT LIVES
}

\author{
LINA MA ${ }^{1}$ AND D. KANNAN ${ }^{2}$ \\ ${ }^{1}$ School of Finance \\ Capital University of Economics and Business \\ Beijing, 100070, P.R. CHINA \\ ${ }^{2}$ Department of Mathematics \\ University of Georgia \\ Athens, Georgia, USA
}

\begin{abstract}
Utilizing the principle of balance between expected gain and expected payment, this work obtains the analytic valuation formula for reverse mortgage. In particular, we provide the formulas for the lump sum payment, joint annuity, increasing (decreasing) annuity, and level annuity of reverse mortgage. We also derive the valuation equation that the variable payment annuities satisfy. We then discuss the monotonicity of the lump sum, annuity, and annuity payment factors with respect to the parameters associated with the home price and the interest rate model. Finally, we analyze the sensitivity of the joint annuity with respect to the parameters associated with the home price, interest rate, and lifetime model. The numerical results show that the average return of home price exerts a dominating influence on the joint annuity, followed by the mean reversion level of interest rate, and both of them have stronger impact on the annuities of younger applicants than those of older applicants. Meanwhile, the initial age of male and that of female produce asymmetrical effect on the joint annuity. Remarkably, the dependence of joint-lifetime significantly affect the joint annuity value. In case that the male and female initial ages are both less than 80 years old, annuity values on average increase approximately $4.5 \%$, and the greatest increment of annuity value approaches $9 \%$.
\end{abstract}

Key Words: reverse mortgage, valuation, joint annuity, jump-diffusion, Vasicek model, lifetime model

Received: October 19, 2018; Accepted: December 7, 2018;

Published: December 8, 2018 doi: 10.12732/dsa.v27i4.13

Dynamic Publishers, Inc., Acad. Publishers, Ltd. https://acadsol.eu/dsa 


\section{INTRODUCTION}

Reverse Mortgage is an inviting financial lending product offered to any senior citizen who owns a house. It is normally categorized by law into two categories, namely collateral reverse mortgage and ownership conversion reserve mortgage, (Ohgaki, 2003). The collateral reverse mortgage is redeemable while the ownership conversion reverse mortgage is not. Home Equity Conversion Mortgage System is a typical collateral reverse mortgage in USA. In a collateral reverse mortgage, the elderly householder borrows annuity like periodical installment mortgage on his/her residential house. With the collateral reverse mortgage, the borrower is able to redeem the reverse mortgage by repaying the loan principal and accumulated interests through property sale at any time from the mortgage's effective date to due date. Rente Viager is a typical ownership conversion reverse mortgage in France. In the case of the ownership conversion reverse mortgage, the borrower enters into a contract with a lending institution to obtain an annuity until his/her death, and at death the pledged property ownership is transferred to the lender.

Since the advent of reverse mortgage, many scholars and practitioners have engaged in research related to this area, mainly on the basic principles, operation modes, feasibility, effectiveness, policies, laws, risks, and valuation. Compared to the valuation problem, other aspects of reverse mortgage are well studied, and we note here that the literature on valuation is not as rich as those on other aspects. We focus, in this article, our attention to the valuation problem. The valuation of reverse mortgage mainly includes three aspects: (1) determining a lump sum and annuity payments that the lender can pay before signing the reverse mortgage contract, (2) pricing the redemption right of the collateral reverse mortgage before signing the reverse mortgage contract, and (3) finding the value of reverse mortgage at any time $t$ after signing the RM contract. The main idea behind the first aspect is to employ the principle of expected balance between gain and payment under the assumption of perfect competition market, which makes the discounted present value of payment of the lender be equal to a certain proportion of discounted present value of the mortgaged property, (see, DiVenti and Herzog (1990), Szymanoski(1994), Tse(1995), Mitchell and Piggott (2004)). The main valuation idea of the last two aspects is to apply the option pricing idea, which regards the mortgaged property as the underlying asset and, the loan principal and accumulated interests as the strike price of underlying asset. (Here, the pledged property is usually assumed to follow a stochastic process or stochastic series.) When the contract expires, the lender or its successor determines whether to execute the option (i.e., redeem the pledged property) according to the difference between the price of pledged property and the loan principle and accumulated interests, see Li et al. (2010) and Tsay et al. (2014). 
The main risks involved with reverse mortgage, as pointed out by Szymanoski (1994), include property-value risk, interest-rate risk, and longevity risk. In order to rationally price reverse mortgage, one must build an appropriate model that takes into account the above mentioned risks. In general, the risk of house price is modeled in two ways. One is to assume directly that the dynamics of house-price is driven by a forward stochastic differential equation, as in Bardhan et al. (2006), Wang et al. (2008), Mizrach (2012), Huang et al. (2011), Chen et al. (2010a), Lee et al. (2012), and Tsay et al. (2014). The other is to fit the time series model based on the historical data of the house price, as discussed by Nothaft et al. (1995), Chinloy et al. (1997), Chen et al. (2010b), and Li et al. (2010). The literature on classical interest rate model mainly includes: the Dothan (1978) model, Vasicek (1977) model, Cox, Ingersoll and Ross (1985) model, Exponential Vasicek model, Hull and White (1990) model, Black and Karasinski (1991) model, Mercurio and Moraleda (2000) model, the CIR ++ model, and the Extended Exponential Vasicek model (Brigo and Mercurio, 2006). There are usually several ways to describe the longevity risk, such as a life table and the force of mortality model. For the classical force of mortality model, refer to de Moivre (1724), Gompertz (1825), Makeham (1860, 1867), Weibull (1951), Heligman and Pollard (1980), and Lee-Carter (1992).

As pointed out earlier, this work focuses on the valuation problem of reverse mortgage. We provide analytic valuation formulas for the lump sum and three different annuity aspects of reverse mortgage. We also derive the valuation equation that the variable payment annuities satisfy. For our analysis, we appeal to the principle of balance between expected gain and expected payment. Taking into account of the influence of the parameters associated with the home-price and interest-rate models, we discuss the monotonicity of the lump sum, annuity, and annuity payment factors. Finally, we analyze the sensitivity of the joint annuity with respect to the parameters associated with the home price, interest rate and lifetime model. Our numerical results show that the average return of home price exerts a dominating influence on the joint annuity, followed by the mean reversion level of interest rate. We observe here that both of them have more impact on the annuities of young applicants than those of old applicants. It is interesting to note that the initial age of male and that of female produce asymmetrical effect on the joint annuity. Remarkably, the dependence of joint-lifetime significantly affects the joint annuity value.

The rest of this article is organized as follows. Section 2 presents the models of risk factors. In Section 3, we first design the reverse mortgage predicated on the ownership conversion with fixed yearly payment until death, and then derive the valuation model for the lump sum and annuity payments under the principle of balance between expected gain and expected payment. Section 4 analyzes the monotonicity of the lump sum, annuity payments, and annuity payment factors with respect to the 
parameters involved in housing price and interest rate models. We provide in Section 5 some numerical results to examine how the housing price risk, interest rate risk, and longevity risk impact the lump sum, annuity payment, and the annuity payment factors. The final section draws conclusions about our findings.

\section{RISK FACTORS}

Our goal is to determine the lump sum and annuity of the reverse mortgage without redemption-right applied by a joint lives. In order to build a suitable model to analyze these factors, we must first explore how to describe the risk factors that the reverse mortgage without redemption-right involves. TOWARD THIS: (1) we employ the jumpdiffusion model to mimic the dynamics of home price, (2) the Vasicek model to drive the instantaneous interest rate, and (3) a bivariate distribution function to describe the dependent longevity risk of a joint-life (i.e. a couple). All our random elements are defined on a complete filtered probability space $\left(\Omega, \mathcal{F}, \mathcal{P},\left\{\mathcal{F}_{t}\right\}_{t \geq 0}\right)$, where $(\Omega, \mathcal{F}, \mathcal{P})$ is a complete probability space and $\left\{\mathcal{F}_{t}\right\}_{t \geq 0}$ is a right continuous increasing family of sub $\sigma$-algebras of $\mathcal{F}$ with all the null events in $\mathcal{F}_{0}$.

\subsection{HOUSE PRICE}

We shall use a jump diffusion to model the risk caused by the house price. We assume that the house price $h(t)(t \geq 0)$ follows the exponential Lévy process

$$
\begin{aligned}
& h(t)=h(0) \exp \left[\int_{0}^{t} \mu_{h}(s) d s-\left(\frac{1}{2} \sigma_{h}^{2}+\lambda_{h} k_{h}\right) t+\sigma_{h} W_{h}(t)+\sum_{i=1}^{N(t)} J_{i}\right], \\
& h(0)=h_{0} .
\end{aligned}
$$

This is a generalization by Lee et al., 2012, of the Merton jump diffusion model (Merton, 1976). HERE:

- the $\mathcal{P}$-standard Brownian motion process $\left\{W_{h}(t), t \geq 0\right\}$ captures the unanticipated instantaneous change of house price.

- the Wiener process $\left\{W_{h}(t)\right\}$ will not capture the abnormal shocks caused by sudden rise or drop in the house price. We model the rise/drop in the house price by independent Gaussian random jumps $\left\{J_{i}, i \geq 0\right\}$ with mean $\mu_{J}$ and variance $\sigma_{J}^{2}$, and we count the number of price jumps during the time interval $(0, t]$ using a Poisson process $\{N(t), t \geq 0\}$ with intensity $\lambda_{h}$.

- We assume that the processes $\left\{W_{h}(t), t \geq 0\right\},\{N(t), t \geq 0\}$, and $\left\{J_{i}, i \geq 0\right\}$ are 
independent.

- The drift coefficient $\mu_{h}(t)$ denotes the average rate of return.

- The diffusion coefficient $\sigma_{h}(>0)$ represents the volatility of the house price.

- The parameter $k_{h}$ is one less than the mean of $\exp \left(J_{i}\right)$, i.e., $k_{h}=\exp \left(\mu_{J}+\frac{1}{2} \sigma_{J}^{2}\right)-1$.

\subsection{INTEREST RATE}

We next assume that the instantaneous short-rate dynamics evolves as Vasicek model (Vasicek, 1977). Specifically, the interest rate process $\{r(t), t \geq 0\}$ is governed by the following stochastic differential equation

$$
d r(t)=\alpha_{r}\left(\mu_{r}-r(t)\right) d t+\sigma_{r} d W_{r}(t), r(0)=r_{0}
$$

where $\left\{W_{r}(t), t \geq 0\right\}$ is a $\mathcal{P}$-standard Brownian motion with $\operatorname{Cov}\left(d W_{r}(t), d W_{h}(t)\right)=$ $\rho_{h r} d t$. We assume that $r_{0}, \alpha_{r}, \mu_{r}, \sigma_{r}$ are positive constants.

Applying Itô's formula to $e^{\alpha_{r} u} r(u)$ and integrating from 0 to $t$, we obtain

$$
r(t)=e^{-\alpha_{r} t} r(0)+\mu_{r}\left(1-e^{-\alpha_{r} t}\right)+\sigma_{r} \int_{0}^{t} e^{-\alpha_{r}(t-u)} d W_{r}(u), t \geq 0 .
$$

The discount factor at time $t$, denoted by $d(t)$, is defined as

$$
d(t):=\exp \left(-\int_{0}^{t} r(s) d s\right) .
$$

After some some trivial computations, we have

$$
\begin{aligned}
& E[d(t)] \\
& =\exp \left\{\left(\frac{\sigma_{r}^{2}}{2 \alpha_{r}^{2}}-\mu_{r}\right) t+\frac{1}{\alpha_{r}}\left(\mu_{r}-r_{0}\right)\left(1-e^{-\alpha_{r} t}\right)+\frac{\sigma_{r}^{2}}{4 \alpha_{r}^{3}}\left[1-\left(2-e^{-\alpha_{r} t}\right)^{2}\right]\right\},
\end{aligned}
$$

see also Norberg (2004).

\subsection{JOINT LIVES}

By the initial time $t=0$ we mean the time at which the reverse mortgage (without redemption-right involving a joint-life) is signed. Let $x_{0}$ and $y_{0}$ represent the age of the husband and wife at time 0 , respectively. Let $X$ and $Y$ be the age-at-death of the husband and wife, respectively. By $F(x, y):=P(X \leq x, Y \leq y)$ we denote the joint distribution function of random vector $(X, Y)$, with $F_{1}(x)$ and $F_{2}(y)$ denoting the respective marginal distributions, (i.e., $F_{1}(x)=F(x,+\infty)$ and $F_{2}(y)=F(+\infty, y)$ ). 
The bivariate distribution function can be specified by a copula function and two marginal distributions; that is,

$$
F(x, y)=C\left(F_{1}(x), F_{2}(y)\right)
$$

where $C$ is a real-valued copula function that provides a link between the marginal distributions and the corresponding bivariate distribution. The copula function can be expressed as, (see Frees et al. (1996)),

$$
C(u, v)=\frac{1}{\alpha} \ln \left[1+\frac{\left(e^{\alpha u}-1\right)\left(e^{\alpha v}-1\right)}{e^{\alpha}-1}\right],
$$

with the two marginal distributions following the Gompertz distribution:

$$
\begin{aligned}
& F_{1}(x)=1-\exp \left[e^{-\frac{m_{1}}{\sigma_{1}}}\left(1-e^{\frac{x}{\sigma_{1}}}\right)\right], \\
& F_{2}(y)=1-\exp \left[e^{-\frac{m_{2}}{\sigma_{2}}}\left(1-e^{\frac{y}{\sigma_{2}}}\right)\right],
\end{aligned}
$$

(see Carrière (1994)). It is easy to see that the marginal density distributions for $X$ and $Y$, respectively denoted by $f_{1}(x)$ and $f_{2}(y)$, are given by

$$
\begin{aligned}
& f_{1}(x)=\frac{1}{\sigma_{1}} e^{\frac{x-m_{1}}{\sigma_{1}}} \exp \left[e^{-\frac{m_{1}}{\sigma_{1}}}\left(1-e^{\frac{x}{\sigma_{1}}}\right)\right], \\
& f_{2}(y)=\frac{1}{\sigma_{2}} e^{\frac{y-m_{2}}{\sigma_{2}}} \exp \left[e^{-\frac{m_{2}}{\sigma_{2}}}\left(1-e^{\frac{y}{\sigma_{2}}}\right)\right] .
\end{aligned}
$$

We consider a bivariate residual lifetime random vector $\left(X-x_{0}, Y-y_{0}\right)$, where $X-x_{0}$ and $Y-y_{0}$ represents the time-until-death of the husband and that of the wife, respectively. The joint distribution function for $\left(X-x_{0}, Y-y_{0}\right)$ is expressed as

$$
F_{c}(x, y)=\frac{1}{p_{0}}\left[F\left(x_{0}+x, y_{0}+y\right)-F\left(x_{0}+x, y_{0}\right)-F\left(x_{0}, y_{0}+y\right)+F\left(x_{0}, y_{0}\right)\right],
$$

where

$$
p_{0}=1-F_{1}\left(x_{0}\right)-F_{2}\left(y_{0}\right)+F\left(x_{0}, y_{0}\right) \text {. }
$$

Let

$$
T_{1}=\min \left\{X-x_{0}, Y-y_{0}\right\}, \quad T_{2}=\max \left\{X-x_{0}, Y-y_{0}\right\},
$$

then the density function $f_{T}(t)$ for $T_{2}$ is

$$
f_{T}(t)=\frac{1}{p_{0}}\left[\frac{d F\left(x_{0}+t, y_{0}+t\right)}{d t}-\frac{d F\left(x_{0}+t, y_{0}\right)}{d t}-\frac{d F\left(x_{0}, y_{0}+t\right)}{d t}\right] .
$$

Abbreviating $\frac{d F\left(x_{0}+t, y_{0}+t\right)}{d t}$ as $\frac{d F}{d t}$, we have

$$
\frac{d F}{d t}=\frac{f_{1}\left(x_{0}+t\right) e^{\alpha F_{1}\left(x_{0}+t\right)}\left(e^{\alpha F_{2}\left(y_{0}+t\right)}-1\right)+f_{2}\left(y_{0}+t\right) e^{\alpha F_{2}\left(y_{0}+t\right)}\left(e^{\alpha F_{1}\left(x_{0}+t\right)}-1\right)}{e^{\alpha}-1+\left(e^{\alpha F_{1}\left(x_{0}+t\right)}-1\right)\left(e^{\alpha F_{2}\left(y_{0}+t\right)}-1\right)},
$$




$$
\begin{aligned}
& \frac{d F\left(x_{0}+t, y_{0}\right)}{d t}=\frac{\left(e^{\alpha F_{2}\left(y_{0}\right)}-1\right) e^{\alpha F_{1}\left(x_{0}+t\right)} f_{1}\left(x_{0}+t\right)}{e^{\alpha}-1+\left(e^{\alpha F_{1}\left(x_{0}+t\right)}-1\right)\left(e^{\alpha F_{2}\left(y_{0}\right)}-1\right)}, \\
& \frac{d F\left(x_{0}, y_{0}+t\right)}{d t}=\frac{\left(e^{\alpha F_{1}\left(x_{0}\right)}-1\right) e^{\alpha F_{2}\left(y_{0}+t\right)} f_{2}\left(y_{0}+t\right)}{e^{\alpha}-1+\left(e^{\alpha F_{1}\left(x_{0}\right)}-1\right)\left(e^{\alpha F_{2}\left(y_{0}+t\right)}-1\right)} .
\end{aligned}
$$

\section{VALUATION OF REVERSE MORTGAGE}

In this section, we will first introduce a reverse mortgage with the joint and $\gamma$ annuities applied by the dependent joint lives. Then, the valuation models are built based on the principle of balance between expected gain and expected payment. Under the two-dimensional Gauss distribution and independence assumptions, we obtain the analytic valuation formulas for the lump sum, joint and $\gamma$ annuities, increasing (decreasing) annuities, and level annuities of reverse mortgage without redemption right, and derive the valuation equation that the variable payment annuities satisfy.

\subsection{REVERSE MORTGAGE WITH JOINT AND $\gamma$ ANNUITIES}

In this subsection, we will design a reverse mortgage with the joint and $\gamma$ annuities. The joint-life contract offers a yearly annuity payment until the last annuitant dies. In this article, the joint-life means a couple. The product that we design has the following basic features:

(I) The lender starts the payments of annuity to the joint annuitants at the beginning of signing the contract. The annuity payment is terminated upon the death of the last annuitant. While both annuitants are alive, the lender pays annuity amount $A$ at the beginning of each year, and $\gamma A$ while only one annuitant is alive.

(II) When the last applicant dies, the lender will take over the annuitant's pledged property, sell it in the market, and keep all of the proceeds from the sale of the property.

The essence of reverse mortgage with the joint and $\gamma$ annuities is to exchange the profit from selling the mortgaged house with the joint-life's annuities until the last annuitant's death. Upon the passing of the last annuitant, the lender will take over the homeowner's mortgaged property and sell it. The cash that is thus acquired is used to repay loan (including annuities and accumulated interests) that the joint annuitants owe to the lender. Reverse mortgage possesses the non-recourse clauses, which is, that the lender may not reclaim the loan against the annuitants' other assets or cash income except for their pledged property. So, the lender will suffer a loss when the 
cash of selling the mortgaged property is less than those annuities and accumulated interests, otherwise the lender will make a profit.

Next, we will demonstrate how the reverse mortgage runs with the joint and $\gamma$ annuities. Assume that the age-at-death of the husband and the wife be $X=65.7$ and $Y=67.9$ years, respectively. Let the initial age be respectively $x_{0}=65$ and $y_{0}=64$ years. Then the loan tenure is $T_{2}=\max \left\{X-x_{0}, Y-y_{0}\right\}=3.9$ years. This implies that the couple claims once cash payment $A$ at the beginning of the first year of the contract. The wife as the last annuitant claims three times cash payments $\gamma A$ at the beginning of the second, third and fourth year of the contract, respectively. When the wife, the last survivor, dies at age of 67.9 years, the lender will take over the pledged house and sell it in the market. Most of the time, it is impossible to sell out the pledged house as soon as the lender takes over it. Thus the time of selling out the pledged house usually lags behind that of taking over the pledged house for a time. In the following valuation models, we will take the delay time into consideration.

\subsection{VALUATION OF REVERSE MORTGAGE WITH JOINT AND $\gamma$ ANNUITIES}

We assume that we are in the perfectly competitive market. We price the reverse mortgage with the joint and $\gamma$ annuity by the principle of balance between expected gain and expected payment. Recall that the terminology principle of balanced expected gain and payment means that the expected discounted present value of future sale of the pledged property is the same as the expected discounted present value of annuities that the lender pays during the whole loan period.

At time $T_{2}$, the lender takes over the annuitants' mortgaged property, and sells it at time $T_{2}+t_{0}$ where $t_{0} \geq 0$ is the delay time between the lender taking over the pledged property and the sale of that property. We assume that $t_{0}$ is fixed (not a random variable). Then the expectation of discounted present value of the sale price of the property (i.e., the lender's expected gain) is

$$
E\left[h\left(T_{2}+t_{0}\right) d\left(T_{2}+t_{0}\right)\right]
$$

where $h(t)$ is the value of the mortgaged property at time $t$ given by the Lévy Equation $(1)$, and $d(t)$ is the discount factor at time $t$ given by the Equation (4).

The expectation of discounted present value of the joint and $\gamma$ annuities during the whole loan period (i.e., the lender's expected payment) is

$$
E\left[\sum_{k=0}^{\left\lfloor T_{1}\right\rfloor} A d(k)+\sum_{k=\left\lfloor T_{1}\right\rfloor+1}^{\left\lfloor T_{2}\right\rfloor} \gamma A d(k)\right]
$$


where $\lfloor x\rfloor$ is the floor function (the largest integer not greater than $x$ ). Then, the principle of balance between expected gain and expected payment yields

$$
E\left[h\left(T_{2}+t_{0}\right) d\left(T_{2}+t_{0}\right)\right]=E\left[\sum_{k=0}^{\left\lfloor T_{1}\right\rfloor} A d(k)+\sum_{k=\left\lfloor T_{1}\right\rfloor+1}^{\left\lfloor T_{2}\right\rfloor} \gamma A d(k)\right] .
$$

In general, the explicit formula of annuity payment is difficult to obtain from the Equation (11). But we can obtain the analytic annuity formula under the twodimensional Gaussian distribution and independence assumption. The following Proposition 1 presents the analytic formula for the expected discounted present value of the mortgaged property at any time $t$.

Proposition 1: Define

$$
Y(t):=\int_{0}^{t}\left[\sigma_{r} e^{-\alpha_{r} s} \int_{0}^{s} e^{\alpha_{r} u} d W_{r}(u)\right] d s .
$$

Assume that (a) the dynamics of home price follows the exponential Lévy process given by the Equation (1), (b) the instantaneous short interest rate is governed by the Equation (2), (c) the joint distribution of $\left(W_{h}(t), Y(t)\right)$ follows the two dimensional Gaussian distribution, and that $(d) \sigma_{h} W_{h}(t)-Y(t)$ is independent of $\sum_{i=1}^{N(t)} J_{i}$. Then, the expectation of discounted present value of the mortgaged property at time-t is given by

$$
E[h(t) d(t)]=G(t) D(t)
$$

where

$$
\begin{gathered}
G(t)=h_{0} \exp \left\{\int_{0}^{t} \mu(s) d s-\sigma_{h} \sigma_{r} \rho_{h r} \frac{1}{\alpha_{r}}\left(t+\frac{1}{\alpha_{r}} e^{-\alpha_{r} t}-\frac{1}{\alpha_{r}}\right)\right\}, \\
D(t)=\exp \left\{\left(\frac{\sigma_{r}^{2}}{2 \alpha_{r}^{2}}-\mu_{r}\right) t+\frac{1}{\alpha_{r}}\left(\mu_{r}-r_{0}\right)\left(1-e^{-\alpha_{r} t}\right)+\frac{\sigma_{r}^{2}}{4 \alpha_{r}^{3}}\left[1-\left(2-e^{-\alpha_{r} t}\right)^{2}\right]\right\} .
\end{gathered}
$$

Proof: see Appendix A.

The Proposition 2 presented below provides the analytic valuation formula for the expected lump sum that the householder can borrow in average at time 0 , and the analytic valuation formula for the joint annuity. In this, the house price $h(t)$, the interest rate $r(t)$, the discount factor $d(t)$, and the survival periods $T_{1}$ and $T_{2}$ are respectively given by the Equations (1), (3), (4), and (7). Also recall that the lump sum is the total cash that the annuitants can obtain in average at the time of signing the reverse mortgage contract.

Proposition 2: Assume that (a) $h(t) d(t),(t \geq 0)$, is independent of $T_{2},(b) r(t)$ is independent of $\left(T_{1}, T_{2}\right)$, and $(c)$ the pledged property is sold at time $T_{2}+t_{0}$. Then: 
(1) The expectation of the lump sum, denoted by $\widetilde{G}$, is

$$
\widetilde{G}=\int_{0}^{+\infty} G\left(x+t_{0}\right) D\left(x+t_{0}\right) f_{T}(x) d x
$$

where $G\left(x+t_{0}\right), D\left(x+t_{0}\right)$ and $f_{T}(x)$ are given by Equations (14), (15) and (8), respectively.

(2) For the joint and $\gamma$ annuity, the fixed amount $A$ of annuity is given by

$$
A=\frac{\widetilde{G}}{\widetilde{F}_{1}}
$$

where

$$
\widetilde{F}_{1}=\sum_{i=0}^{+\infty} D(i)\left[1-(1-\gamma) F_{c}(i,+\infty)-(1-\gamma) F_{c}(+\infty, i)+(1-2 \gamma) F_{c}(i, i)\right],
$$

and $F_{c}(x, y)$ is given by the Equation (6).

Proof: Since the lender's only gain is from the proceeds of selling the homeowner's pledged house, with the principle of balance between expected gain and expected payment, the lump sum that the applicants can borrow at time $t=0$ of signing the reverse mortgage contract is $h\left(T_{2}+t_{0}\right) d\left(T_{2}+t_{0}\right)$, which is a random variable. Further, noting that $h(t) d(t)(t \geq 0)$ is independent of $T_{2}$, we get

$$
\begin{aligned}
\widetilde{G} & =E\left[h\left(T_{2}+t_{0}\right) d\left(T_{2}+t_{0}\right)\right] \\
& =\int_{0}^{+\infty} E\left[h\left(x+t_{0}\right) d\left(x+t_{0}\right)\right] f_{T}(x) d x \\
& =\int_{0}^{+\infty} G\left(x+t_{0}\right) D\left(x+t_{0}\right) f_{T}(x) d x,
\end{aligned}
$$

where $G\left(x+t_{0}\right)$ and $D\left(x+t_{0}\right)$ can be characterized by replacing $t$ with $x+t_{0}$ in Equations (14) and (15), respectively, and $f_{T}(x)$ denotes the probability density function for $T_{2}$ given by the Equation (8).

From the independence of $r(t)$ and $\left(T_{1}, T_{2}\right)$, we have

$$
\begin{aligned}
& E\left[\sum_{k=0}^{\left\lfloor T_{1}\right\rfloor} A d(k)+\sum_{k=\left\lfloor T_{1}\right\rfloor+1}^{\left\lfloor T_{2}\right\rfloor} \gamma A d(k)\right] \\
= & E\left[\sum_{i=0}^{+\infty} \sum_{k=0}^{i} A d(k) \mathbf{1}_{\left\{\left\lfloor T_{1}\right\rfloor=i\right\}}\right]+E\left[\sum_{i=0}^{+\infty} \sum_{j=i+1}^{+\infty} \sum_{k=i+1}^{j} \gamma A d(k) \mathbf{1}_{\left.\left\{\left\lfloor T_{1}\right\rfloor=i,\left\lfloor T_{2}\right\rfloor=j\right\}\right]}\right] \\
= & A \sum_{i=0}^{+\infty} \sum_{k=0}^{i} E[d(k)] P\left(\left\lfloor T_{1}\right\rfloor=i\right)+\gamma A \sum_{i=0}^{+\infty} \sum_{j=i+1}^{+\infty} \sum_{k=i+1}^{j} E[d(k)] P\left(\left\lfloor T_{1}\right\rfloor=i,\left\lfloor T_{2}\right\rfloor=j\right)
\end{aligned}
$$




$$
\begin{aligned}
& =A \sum_{i=0}^{+\infty} D(i) P\left(T_{1} \geq i\right)+\gamma A \sum_{i=0}^{+\infty} D(i) P\left(T_{1}<i, T_{2} \geq i\right) \\
& =A \cdot \widetilde{F}_{1}
\end{aligned}
$$

where $D(k)$ is characterized as in (15). Recalling that the probability density function for $T_{2}$ is given by the Relation (8), we get the Equation (17). The proof is complete.

\subsection{VALUATION OF REVERSE MORTGAGE WITH VARIABLE PAYMENT ANNUITIES}

By the terminology phrase reverse mortgage with variable payment annuity one means that the lender starts the payments of annuity to the joint lives at the beginning of signing the contract until the death of the last survivor, and that the annuity payment amount at year $k,(k \geq 1)$, is $A_{k}$. Here, if the last annuitant passes away at $k$-th year, then a total amount $\sum_{i=1}^{k} A_{i}$ of annuity payments has been paid. The increasing or decreasing annuity is a special case of the variable payment annuity with $A_{k} \equiv A_{0}+d \cdot k(k=1,2, \ldots)$. At the beginning of $k$-th period, the annuity payment is $A_{0}+d \cdot k$, as long as at least one of the annuitants is alive. In the following, we call $A_{0}$ the basic annuity, and $d$ the annuity increment. The level annuity is a special case of the joint and $\gamma$ annuity with $\gamma=1$, and it is also a special case of the variable payment annuity with $A_{k}$ being the same constant for all $k \geq 1$. For the level annuity, the fixed amount $A^{*}$ of annuity is paid until the death of the last survivor. Because the analysis needed in this subsection parallels that of the previous subsection we omit the proof of Proposition 3 below.

Proposition 3: Assume that $(a) h(t) d(t)(t \geq 0)$ is independent of $T_{2},(b) r(t)$ is also independent of $T_{2}$, and (c) The pledged property is sold at time $T_{2}+t_{0}$. Then:

(1) For the variable payment annuity, the annuity payments $A_{k}(k=1,2, \ldots)$ satisfy the following valuation equation

$$
\int_{0}^{+\infty} G\left(x+t_{0}\right) D\left(x+t_{0}\right) f_{T}(x) d x=\sum_{k=0}^{+\infty} A_{k+1} D(k) P\left(T_{2} \geq k\right),
$$

where

$$
P\left(T_{2} \geq k\right)=1-F_{c}(k, k),
$$

and $D(k)$ is given by Equation (15).

(2) For the increasing (decreasing) annuity, $A_{0}$ and $d$ are determined by the simultaneous equations

$$
A_{0}=\frac{\widetilde{G}-d \cdot \widetilde{F}_{3}}{\widetilde{F}_{2}}, \quad d=\frac{\widetilde{G}-A_{0} \cdot \widetilde{F}_{2}}{\widetilde{F}_{3}},
$$


where

$$
\widetilde{F}_{2}=\sum_{k=0}^{+\infty} D(k) P\left(T_{2} \geq k\right), \quad \widetilde{F}_{3}=\sum_{k=0}^{+\infty} k D(k) P\left(T_{2} \geq k\right),
$$

and $D(k), \widetilde{G}$ and $P\left(T_{2} \geq k\right)$ are respectively defined by Equations (15), (16) and (20).

(3) For the level annuity, the fixed annuity amount $A^{*}$ is given by

$$
A^{*}=\frac{\widetilde{G}}{\widetilde{F}_{2}}
$$

where $\widetilde{F}_{2}$ is given by Equation (22).

\section{EFFECT OF PARAMETERS ON THE ANNUITY}

We analyze in this and the following sections, how the parameters associated with the house price, interest rate, and the delay duration in selling the pledged house would affect the various annuity payments, (particularly, annuity payments, lump sum payments, and annuity payment factors).

\subsection{MONOTONICITY W.R.T THE PARAMETERS OF HOUSE PRICE}

In the following, we assume that the rate of return $\mu_{h}(t) \equiv \mu_{h}$ of the house price (that is the drift coefficient) is held constant. The next Proposition 4 analyzes the monotonicity of the annuity payment, lump sum, and annuity payment factors w.r.t the parameters related with the house price model, including the average return rate $\mu_{h}$, the volatility $\sigma_{h}$, the initial house price $h_{0}$, the correlation coefficient between the Brownian motion driving the house price and those driving the interest rate $\rho_{h r}$, and the delay time in selling the pledged house $t_{0}$. For the descriptions of the parameters $\mu_{h}, \sigma_{h}, \rho_{h r}$, and $h_{0}$ connected to the house price, we refer to Section 2.

Proposition 4: With respect to the parameters $\mu_{h}, \sigma_{h}, \rho_{h r}$, and $h_{0}$ of the house price, the joint and $\gamma$ annuity payment $A$, the basic annuity $A_{0}$, the fixed annuity increment $d$ of the increasing (decreasing) annuity, the level annuity payment $A^{*}$, the lump sum $\widetilde{G}$, and the annuity payment factors $\widetilde{F}_{i}(i=1,2,3)$ (given by Propositions 2 and 3) have the following properties:

4.1. PARAMETER $\mu_{h}$ : (a) The annuity payment factors $\widetilde{F}_{i}(i=1,2,3)$ are independent of $\mu_{h}$; (b) The lump sum $\widetilde{G}$ is an increasing function of $\mu_{h}$; and (c) The A, $A_{0}, d$ and $A^{*}$ are all increasing functions of $\mu_{h}$. 
4.2. PARAmeter $\sigma_{h}$ : (a) The annuity payment factors $\widetilde{F}_{i}(i=1,2,3)$ are independent of the volatility $\sigma_{h}$ of the house price. (b) If $\rho_{h r}>0, \sigma_{r}>0$ and $\alpha_{r} \neq 0$, then the lump sum $\widetilde{G}$ is a decreasing function of $\sigma_{h}$. (c) If $\rho_{h r}<0, \sigma_{r}>0$ and $\alpha_{r} \neq 0$, then the lump sum $\widetilde{G}$ is an increasing function of $\sigma_{h}$. (d) If $\rho_{h r}>0, \sigma_{r}>0$ and $\alpha_{r} \neq 0$, then $A, A_{0}, d$ and $A^{*}$ all are decreasing functions of $\sigma_{h}$. (e) If $\rho_{h r}<0, \sigma_{r}>0$ and $\alpha_{r} \neq 0$, then $A, A_{0}, d$ and $A^{*}$ all are increasing functions of $\sigma_{h}$.

4.3. PARAmeter $\rho_{h r}$ : (a) The annuity payment factors $\widetilde{F}_{i}, i=1,2,3$, are independent of $\rho_{h r}$. (b) If $\sigma_{h}>0, \sigma_{r}>0$ and $\alpha_{r} \neq 0$, then the lump sum $\widetilde{G}$ is a decreasing function of $\rho_{h r}$. (c) If $\sigma_{h}>0, \sigma_{r}>0$ and $\alpha_{r} \neq 0$, then $A, A_{0}, d$ and $A^{*}$ are all decreasing functions of $\rho_{h r}$.

4.4. PARAmeter $h_{0}$ : (a) The annuity payment factors $\widetilde{F}_{i}, i=1,2,3$, are independent of the initial house price $h_{0}$. (b) The lump sum $\widetilde{G}$ is an increasing function of $h_{0}$. (c) The $A, A_{0}, d$ and $A^{*}$ are all increasing functions of $h_{0}$.

Proof: From the definitions of the annuity payment factors $\widetilde{F}_{i}(i=1,2,3)$ (see Relations (18) and (22)), we note that these two annuity payment factors are independent of $\mu_{h}$.

Noting that $D\left(x+t_{0}\right)$ and $f_{T}(x)$ do not depend on $\mu_{h}$, the partial derivative of the integrand in the definition of $\widetilde{G}$ (see Relation (16)), is

$$
\frac{\partial\left[G\left(x+t_{0}\right) D\left(x+t_{0}\right) f_{T}(x)\right]}{\partial \mu_{h}}=\left(x+t_{0}\right) G\left(x+t_{0}\right) D\left(x+t_{0}\right) f_{T}(x) .
$$

Since $G\left(x+t_{0}\right)>0, D\left(x+t_{0}\right)>0, f_{T}(x) \geq 0$ and $x+t_{0} \geq 0$, this implies that the lump sum $\widetilde{G}$ is an increasing function of $\mu_{h}$.

Furthermore, from the Equations (17), (21) and (23), we note that $A, A_{0}, d$ and $A^{*}$ are increasing functions of $\mu_{h}$. Thus, Part 4.1 of the proposition is proved.

From the Equations (18) and (22), defining the annuity payment factors $\widetilde{F}_{i}(i=$ $1,2,3)$ we see that these annuity payment factors are independent of $\sigma_{h}$.

Define

$$
g_{1}(z):=\frac{1}{\alpha_{r}}\left[-z+\frac{1}{\alpha_{r}}\left(1-e^{-\alpha_{r} z}\right)\right] .
$$

Noting that $D\left(x+t_{0}\right)$ and $f_{T}(x)$ do not depend on $\sigma_{h}$, the partial derivative of the integrand in the definition of $\widetilde{G}$ is

$$
\frac{\partial\left[G\left(x+t_{0}\right) D\left(x+t_{0}\right) f_{T}(x)\right]}{\partial \sigma_{h}}=\sigma_{r} \rho_{h r} G\left(x+t_{0}\right) D\left(x+t_{0}\right) f_{T}(x) g_{1}\left(x+t_{0}\right),
$$

where $g_{1}\left(x+t_{0}\right)=\frac{1}{\alpha_{r}}\left[-\left(x+t_{0}\right)+\frac{1}{\alpha_{r}}\left(1-e^{-\alpha_{r}\left(x+t_{0}\right)}\right)\right]$.

In case that $\alpha_{r} \neq 0$ and $z \geq 0$, we have $g_{1}(z) \leq 0$. Thus, Part 4.2 of the proposition is proved. 
Since $D\left(x+t_{0}\right)$ and $f_{T}(x)$ are free from $\rho_{h r}$, the partial derivative w.r.t. $\rho_{h r}$ of the integrand in the definition of $\widetilde{G}$ is

$$
\frac{\partial\left[G\left(x+t_{0}\right) D\left(x+t_{0}\right) f_{T}(x)\right]}{\partial \rho_{h r}}=\sigma_{h} \sigma_{r} G\left(x+t_{0}\right) D\left(x+t_{0}\right) f_{T}(x) g_{1}\left(x+t_{0}\right) .
$$

Noting that $g_{1}(z) \leq 0$ in case of $z \geq 0, \alpha_{r} \neq 0$, Part 4.3 follows.

Since the Part 4.4 is obvious, we omit its proof.

Proposition 5: With respect to the delay time $t_{0}$, the factors $A, A_{0}, d, A^{*}, \widetilde{G}$, and $\widetilde{F}_{i}(i=1,2,3)$ have the following properties:

(a) The annuity payment factors $\widetilde{F}_{i}(i=1,2,3)$ do not depend on $t_{0}$.

(b) Now set

$$
\begin{gathered}
\Delta=\left(\mu_{r}-r_{0}+\frac{\sigma_{h} \sigma_{r} \rho_{h r}}{\alpha_{r}}\right)^{2}+\frac{2 \sigma_{r}^{2}\left(r_{0}-\mu_{h}\right)}{\alpha_{r}^{2}}, \\
z_{1}=-\frac{\alpha_{r}^{2}}{\sigma_{r}^{2}}\left[\mu_{r}-r_{0}-\frac{\sigma_{r}^{2}}{\alpha_{r}^{2}}+\frac{\sigma_{h} \sigma_{r} \rho_{h r}}{\alpha_{r}}+\sqrt{\Delta}\right],
\end{gathered}
$$

and

$$
z_{2}=-\frac{\alpha_{r}^{2}}{\sigma_{r}^{2}}\left[\mu_{r}-r_{0}-\frac{\sigma_{r}^{2}}{\alpha_{r}^{2}}+\frac{\sigma_{h} \sigma_{r} \rho_{h r}}{\alpha_{r}}-\sqrt{\Delta}\right] .
$$

(b-1) If any one of the following conditions is satisfied

$$
\begin{aligned}
& \Delta \leq 0 \\
& \Delta \geq 0, \alpha_{r}>0, z_{1} \geq 1 \\
& \Delta \geq 0, \alpha_{r}>0, z_{2} \leq 0
\end{aligned}
$$

then the lump sum $\widetilde{G}$ is an increasing function of $t_{0}$. Also, the quantities $A, A_{0}, d$ and $A^{*}$ are increasing functions of $t_{0}$.

(b-2) If

$$
\Delta \geq 0, \alpha_{r}>0, z_{1} \leq 0, z_{2} \geq 1
$$

holds, then the lump sum $\widetilde{G}$ is a decreasing function of $t_{0}$. The quantities $A, A_{0}, d$ and $A^{*}$ are also decreasing functions of $t_{0}$.

Proof: Define

$$
g_{2}(z):=\frac{\sigma_{r}^{2}}{2 \alpha_{r}^{2}} z^{2}+\beta_{1} z+\beta_{0}, \quad(-\infty<z<+\infty),
$$

where

$$
\beta_{0}=\mu_{h}-\mu_{r}-\frac{\sigma_{h} \sigma_{r} \rho_{h r}}{\alpha_{r}}+\frac{\sigma_{r}^{2}}{2 \alpha_{r}^{2}},
$$




$$
\beta_{1}=\mu_{r}-r_{0}+\frac{\sigma_{h} \sigma_{r} \rho_{h r}}{\alpha_{r}}-\frac{\sigma_{r}^{2}}{\alpha_{r}^{2}}
$$

The partial derivative of the integrand in the definition of $\widetilde{G}$ is

$$
\frac{\partial\left[G\left(x+t_{0}\right) D\left(x+t_{0}\right) f_{T}(x)\right]}{\partial t_{0}}=G\left(x+t_{0}\right) D\left(x+t_{0}\right) f_{T}(x) g_{2}\left(e^{-\alpha_{r}\left(x+t_{0}\right)}\right),
$$

where

$$
g_{2}\left(e^{-\alpha_{r}\left(x+t_{0}\right)}\right)=\frac{\sigma_{r}^{2}}{2 \alpha_{r}^{2}} e^{-2 \alpha_{r}\left(x+t_{0}\right)}+\beta_{1} e^{-\alpha_{r}\left(x+t_{0}\right)}+\beta_{0} .
$$

The minimum of $g_{2}(z)$ is $-\frac{\alpha_{r}^{2}}{2 \sigma_{r}^{2}} \Delta$, ( $\Delta$ given by Equation (25)). If the condition $\Delta \leq 0$ holds, we then have $g_{2}(z) \geq 0$, and thus $\widetilde{G}$ is an increasing function of $t_{0}$.

Recall the definitions of $z_{1}$ and $z_{2}$ given above by the Relations (26) and (27), respectively. Now, if the condition $\Delta \geq 0$ holds, then $g_{2}\left(z_{i}\right)=0, i=1,2$. Moreover, it is obvious that $0<\exp \left(-\alpha_{r}\left(x+t_{0}\right)\right) \leq 1$ whenever $\alpha_{r}>0$ and $x+t_{0} \geq 0$. Thus the lump sum $\widetilde{G}$ is a decreasing function of $t_{0}$ if the Condition (28) holds. One similarly obtains the rest of the properties in Part (b-1).

\subsection{MONOTONICITY W.R.T PARAMETERS OF INTEREST RATE}

The following Proposition 6 analyzes how the annuity payment, lump sum payment, and the annuity payment factors vary with the parameters involved in the interest rate model, including the initial interest rate $r_{0}$, the mean reversion level $\mu_{r}$, and the volatility $\sigma_{r}$.

Proposition 6: With respect to the parameters of the interest rate model, the factors $A, A_{0}, d, A^{*}, \widetilde{G}, \widetilde{F}_{i}(i=1,2,3)$ have the following properties:

6.1. PARAmeter $r_{0}$ : If $\alpha_{r} \neq 0$, then $\widetilde{G}, \widetilde{F}_{i},(i=1,2,3)$, are decreasing functions of $r_{0}$.

6.2. PARAmeter $\mu_{r}$ : If $\alpha_{r}>0$, then $\widetilde{G}, \widetilde{F}_{i},(i=1,2,3)$, are decreasing functions of $\mu_{r}$. If the opposite case $\alpha_{r}<0$ holds, then $\widetilde{G}, \widetilde{F}_{i},(i=1,2,3)$, are increasing functions of $\mu_{r}$.

6.3. PARAmeter $\sigma_{r}$ : (a) If $\alpha_{r}>0, \sigma_{h}>0$ and $\rho_{h r} \geq 0$, then $\widetilde{G}$ is a decreasing function of $\sigma_{r}$ in the interval $\sigma_{r} \in\left(0, \sigma_{h} \rho_{h r} \alpha_{r}\right]$. If $\alpha_{r}>0, \sigma_{h}>0$ and $\rho_{h r} \leq 0$, then $\widetilde{G}$ is an increasing functions of $\sigma_{r}$.

(b) In case of $\alpha_{r} \neq 0, \sigma_{r}>0$, then $\widetilde{F}_{i},(i=1,2,3)$, are increasing functions of $\sigma_{r}$. 
(c) If $\alpha_{r}>0, \sigma_{h}>0$ and $\rho_{h r} \geq 0$, then $A, A_{0}$, $d$ and $A^{*}$ are decreasing functions of $\sigma_{r}$ in the interval $\sigma_{r} \in\left(0, \sigma_{h} \rho_{h r} \alpha_{r}\right]$.

Proof: Noting that both $G\left(x+t_{0}\right)$ and $f_{T}(x)$ are independent of $r_{0}$, the partial derivative w.r.t $r_{0}$ of the integrand in the definition of $\widetilde{G}$ is

$$
\frac{\partial\left[G\left(x+t_{0}\right) D\left(x+t_{0}\right) f_{T}(x)\right]}{\partial r_{0}}=-\frac{1}{\alpha_{r}}\left[1-e^{-\alpha_{r}\left(x+t_{0}\right)}\right] G\left(x+t_{0}\right) D\left(x+t_{0}\right) f_{T}(x) .
$$

The partial derivatives w.r.t $r_{0}$ of the annuity payment factors $\widetilde{F}_{i},(i=1,2,3)$, are

$$
\begin{aligned}
& \frac{\partial \widetilde{F}_{1}}{\partial r_{0}}=-\frac{1}{\alpha_{r}} \sum_{k=1}^{+\infty}\left(1-e^{-\alpha_{r} k}\right) D(k)\left[P\left(T_{1} \geq k\right)+\gamma P\left(T_{1}<k, T_{2} \geq k\right)\right] \\
& \frac{\partial \widetilde{F}_{2}}{\partial r_{0}}=-\frac{1}{\alpha_{r}} \sum_{k=1}^{+\infty}\left(1-e^{-\alpha_{r} k}\right) D(k) P\left(T_{2} \geq k\right) \\
& \frac{\partial \widetilde{F}_{3}}{\partial r_{0}}=-\frac{1}{\alpha_{r}} \sum_{k=1}^{+\infty} k\left(1-e^{-\alpha_{r} k}\right) D(k) P\left(T_{2} \geq k\right)
\end{aligned}
$$

Since $\frac{1}{\alpha_{r}}\left(1-e^{-\alpha_{r} z}\right) \geq 0$ whenever $\alpha_{r} \neq 0$ and $z \geq 0$, we obtain Part 6.1 of the Proposition.

Define

$$
g_{3}(z):=-z+\frac{1}{\alpha_{r}}\left(1-e^{-\alpha_{r} z}\right)
$$

It is obvious that

$$
\frac{\partial D(x)}{\partial \mu_{r}}=D(x) g_{3}(x) .
$$

Since $G\left(x+t_{0}\right)$ and $f_{T}(x)$ are free from $\mu_{r}$, the partial derivative w.r.t. $\mu_{r}$ of the integrand in the definition of $\widetilde{G}$ is

$$
\frac{\partial\left[G\left(x+t_{0}\right) D\left(x+t_{0}\right) f_{T}(x)\right]}{\partial \mu_{r}}=G\left(x+t_{0}\right) D\left(x+t_{0}\right) f_{T}(x) g_{3}\left(x+t_{0}\right),
$$

where $g_{3}\left(x+t_{0}\right)=-\left(x+t_{0}\right)+\frac{1}{\alpha_{r}}\left(1-e^{-\alpha_{r}\left(x+t_{0}\right)}\right)$.

Since $g_{3}(z) \leq 0$ in case of $\alpha_{r}>0, z \geq 0$, and $g_{3}(z) \geq 0$ in case of $\alpha_{r}<0, z \geq 0$, we obtain Part 6.2.

For $-\infty<z<+\infty$, define

$$
\begin{aligned}
& g_{4}(z)=-\frac{\sigma_{r}}{2 \alpha_{r}^{3}} e^{-2 \alpha_{r} z}+\left(\frac{2 \sigma_{r}}{\alpha_{r}^{3}}-\frac{\sigma_{h} \rho_{h r}}{\alpha_{r}^{2}}\right) e^{-\alpha_{r} z} \\
&+\left(\frac{\sigma_{r}}{\alpha_{r}^{2}}-\frac{\sigma_{h} \rho_{h r}}{\alpha_{r}}\right) z+\left(\frac{\sigma_{h} \rho_{h r}}{\alpha_{r}^{2}}-\frac{3 \sigma_{r}}{2 \alpha_{r}^{3}}\right), \\
& g_{5}(y)=\frac{1}{\alpha_{r}}\left[\frac{\sigma_{r}}{\alpha_{r}} y^{2}+\left(\sigma_{h} \rho_{h r}-\frac{2 \sigma_{r}}{\alpha_{r}}\right) y+\left(\frac{\sigma_{r}}{\alpha_{r}}-\sigma_{h} \rho_{h r}\right)\right] .
\end{aligned}
$$


We have $g_{5}(y)$ has two zero point $y_{1}=1-\frac{\sigma_{h} \rho_{h r} \alpha_{r}}{\sigma_{r}}$ and $y_{2}=1$ in case of $\sigma_{h} \rho_{h r} \geq 0$; $g_{5}(y)$ has two zero point $y_{1}=1$ and $y_{2}=1-\frac{\sigma_{h} \rho_{h r} \alpha_{r}}{\sigma_{r}}$ in case of $\sigma_{h} \rho_{h r} \leq 0$.

The derivation of $g_{4}(z)$ w.r.t $z$ is

$$
\frac{d g_{4}(z)}{d z}=\frac{1}{\alpha_{r}}\left[\frac{\sigma_{r}}{\alpha_{r}} e^{-2 \alpha_{r} z}+\left(\sigma_{h} \rho_{h r}-\frac{2 \sigma_{r}}{\alpha_{r}}\right) e^{-\alpha_{r} z}+\left(\frac{\sigma_{r}}{\alpha_{r}}-\sigma_{h} \rho_{h r}\right)\right]=g_{5}\left(e^{-\alpha_{r} z}\right),
$$

Note that $0<e^{-\alpha_{r} z} \leq 1$ in case of $z \in[0,+\infty), \alpha_{r}>0$. In case of $z \in$ $[0,+\infty), \alpha_{r}>0, \sigma_{h}>0$ and $\rho_{h r} \geq 0$, we have $g_{5}\left(e^{-\alpha_{r} z}\right) \leq 0$ in the interval $\sigma_{r} \in\left(0, \sigma_{h} \rho_{h r} \alpha_{r}\right]$, then $g_{4}(z) \leq g_{4}(0)=0$ in the interval $\sigma_{r} \in\left(0, \sigma_{h} \rho_{h r} \alpha_{r}\right]$. In case of $z \in[0,+\infty), \alpha_{r}>0, \sigma_{h}>0$ and $\rho_{h r} \leq 0$, we have $g_{5}\left(e^{-\alpha_{r} z}\right) \geq 0$, then $g_{4}(z)$ is an increasing function of $z$ and $g_{4}(z) \geq g_{4}(0)=0$.

Noting that $G\left(x+t_{0}\right)$ and $f_{T}(x)$ do not depend on $\sigma_{r}$, the partial derivative w.r.t $\sigma_{r}$ of the integrand in the definition of $\widetilde{G}$ is

$$
\frac{\partial\left[G\left(x+t_{0}\right) D\left(x+t_{0}\right) f_{T}(x)\right]}{\partial \sigma_{r}}=G\left(x+t_{0}\right) D\left(x+t_{0}\right) f_{T}(x) g_{4}\left(x+t_{0}\right) .
$$

Define

$$
g_{6}(z):=z+\left[1-\left(2-e^{-\alpha_{r} z}\right)^{2}\right] \frac{1}{2 \alpha_{r}} .
$$

The partial derivatives w.r.t $\sigma_{r}$ of the annuity payment factors are

$$
\begin{aligned}
\frac{\partial \widetilde{F}_{1}}{\partial \sigma_{r}} & =\frac{\sigma_{r}}{\alpha_{r}^{2}} \sum_{k=1}^{+\infty} D(k) g_{6}(k)\left[P\left(T_{1} \geq k\right)+\gamma P\left(T_{1}<k, T_{2} \geq k\right)\right], \\
\frac{\partial \widetilde{F}_{2}}{\partial \sigma_{r}} & =\frac{\sigma_{r}}{\alpha_{r}^{2}} \sum_{k=1}^{+\infty} D(k) g_{6}(k) P\left(T_{2} \geq k\right), \\
\frac{\partial \widetilde{F}_{3}}{\partial \sigma_{r}} & =\frac{\sigma_{r}}{\alpha_{r}^{2}} \sum_{k=1}^{+\infty} k D(k) g_{6}(k) P\left(T_{2} \geq k\right) .
\end{aligned}
$$

Noting that $g_{6}(z) \geq 0$ in case of $z \in[0,+\infty)$, we get Part 6.3. This completes the proof.

\section{NUMERICAL EXPERIMENT}

In this section, we illustrate the impact of risks involved in the house price, the interest rate, and the longevity on the annuity payment on the valuation.of reverse mortgage Table 1 below provides, as the standard case, the parametric values involved in the models of house price, interest rate, and lifetime. The values of the parameters $\left(m_{1}, m_{2}, \sigma_{1}, \sigma_{2}, \alpha\right)$ come from the bivariate distribution function of the joint lifetimes, (see Frees et al., 1996). For concreteness of exposition, we assume that the initial age of the male is two years greater than that of the female, that is, $x_{0}=y_{0}+2$. 
Table 1: Parameters of the standard case

\begin{tabular}{c|c|c|c|c|c|c|c|c}
\hline Para & $\mu_{h}$ & $\sigma_{h}$ & $\rho_{h r}$ & $h_{0}$ & $t_{0}$ & $r_{0}$ & $\mu_{r}$ & $\sigma_{r}$ \\
\hline Value & 0.04 & 0.08 & 0.3 & $\$ 100$ & 0 & 0.04 & 0.06 & 0.01 \\
\hline Para & $\alpha_{r}$ & $y_{0}$ & $m_{1}$ & $m_{2}$ & $\sigma_{1}$ & $\sigma_{2}$ & $\alpha$ & $\gamma$ \\
\hline Value & 0.5 & $x_{0}-2$ & 85.82 & 89.40 & 9.98 & 8.12 & -3.367 & 0.5 \\
\hline
\end{tabular}

\subsection{EFFECT OF HOUSE PRICE ON ANNUITY VALUES}

Table 2: Effect of house price on annuity values

\begin{tabular}{c|ccccccccccc}
\hline$x_{0}$ & 50 & 55 & 60 & 65 & 70 & 75 & 80 & 85 & 90 & 95 & 100 \\
\hline$\mu_{h}=0.01$ & 1.072 & 1.429 & 1.913 & 2.578 & 3.497 & 4.793 & 6.684 & 9.586 & 14.333 & 22.413 & 35.177 \\
$\mu_{h}=0.025$ & 1.833 & 2.281 & 2.865 & 3.632 & 4.659 & 6.067 & 8.072 & 11.087 & 15.933 & 24.065 & 36.790 \\
$\mu_{h}=0.04$ & 3.193 & 3.708 & 4.356 & 5.187 & 6.276 & 7.745 & 9.809 & 12.877 & 17.757 & 25.876 & 38.505 \\
$\mu_{h}=0.055$ & 5.658 & 6.124 & 6.722 & 7.504 & 8.545 & 9.969 & 11.993 & 15.02 & 19.844 & 27.866 & 40.329 \\
$\mu_{h}=0.07$ & 10.191 & 10.271 & 10.52 & 10.989 & 11.755 & 12.939 & 14.753 & 17.594 & 22.235 & 30.055 & 42.273 \\
\hline$\sigma_{h}=0.001$ & 3.247 & 3.762 & 4.411 & 5.242 & 6.331 & 7.798 & 9.861 & 12.927 & 17.803 & 25.916 & 38.535 \\
$\sigma_{h}=0.1$ & 3.179 & 3.694 & 4.342 & 5.173 & 6.262 & 7.731 & 9.796 & 12.865 & 17.746 & 25.866 & 38.497 \\
$\sigma_{h}=0.2$ & 3.112 & 3.626 & 4.274 & 5.105 & 6.194 & 7.664 & 9.73 & 12.802 & 17.687 & 25.816 & 38.459 \\
$\sigma_{h}=0.3$ & 3.046 & 3.559 & 4.207 & 5.038 & 6.127 & 7.597 & 9.665 & 12.739 & 17.629 & 25.767 & 38.42 \\
$\sigma_{h}=0.4$ & 2.982 & 3.494 & 4.141 & 4.971 & 6.061 & 7.531 & 9.6 & 12.677 & 17.572 & 25.717 & 38.382 \\
\hline$\rho_{h r}=-1$ & 3.438 & 3.955 & 4.603 & 5.433 & 6.519 & 7.984 & 10.041 & 13.099 & 17.961 & 26.050 & 38.638 \\
$\rho_{h r}=-0.5$ & 3.342 & 3.858 & 4.506 & 5.337 & 6.425 & 7.891 & 9.951 & 13.013 & 17.882 & 25.983 & 38.587 \\
$\rho_{h r}=0$ & 3.248 & 3.763 & 4.412 & 5.243 & 6.331 & 7.799 & 9.862 & 12.928 & 17.804 & 25.916 & 38.535 \\
$\rho_{h r}=0.5$ & 3.156 & 3.671 & 4.319 & 5.151 & 6.240 & 7.709 & 9.774 & 12.844 & 17.726 & 25.850 & 38.484 \\
$\rho_{h r}=1$ & 3.068 & 3.582 & 4.229 & 5.060 & 6.150 & 7.619 & 9.686 & 12.760 & 17.649 & 25.783 & 38.433 \\
\hline$h_{0}=100$ & 3.193 & 3.708 & 4.356 & 5.187 & 6.276 & 7.745 & 9.809 & 12.877 & 17.757 & 25.876 & 38.505 \\
$h_{0}=200$ & 6.385 & 7.415 & 8.712 & 10.375 & 12.552 & 15.489 & 19.618 & 25.755 & 35.514 & 51.752 & 77.009 \\
$h_{0}=300$ & 9.578 & 11.123 & 13.068 & 15.562 & 18.828 & 23.234 & 29.426 & 38.632 & 53.272 & 77.628 & 115.514 \\
$h_{0}=400$ & 12.771 & 14.830 & 17.424 & 20.749 & 25.105 & 30.979 & 39.235 & 51.509 & 71.029 & 103.505 & 154.019 \\
$h_{0}=500$ & 15.963 & 18.538 & 21.780 & 25.936 & 31.381 & 38.723 & 49.044 & 64.387 & 88.786 & 129.381 & 192.523 \\
\hline
\end{tabular}

We start the numerical analysis of how the parameters of the house price model and initial age impact the joint annuity and $\gamma$ annuity, while we fix the other parametric values. Table 2 supports the following analysis.

(a) Parameter $\mu_{h}$, the average return of house price: (1) As the initial age is fixed, the annuity increases significantly with the increase of the average return rate of house price $\mu_{h}$; this agrees with the theory established by Proposition 4 . Indeed, this is reasonable. After all, the higher average return rate of house price implies the higher average gains that can be obtained by the lender when selling the mortgaged property in future. With the fair valuation principle, the lender is bound to pay enhanced annuities to the annuitants. (2) Compared to the applicant with higher initial age, the mean return has a stronger impact on the annuity of the annuitant with lower initial age. As the initial age increases, the annuity under different average return rates are stabilizing. While the average return rate of house price $\mu_{h}$ remains 
unchanged, the annuity increases with the increase of male initial age $x_{0}$.

(b) Parameter $\sigma_{h}$, the volatility in house price: (1) When the initial age is fixed, the annuity decreases with the increase of $\sigma_{h}$, (as supported by Proposition 4). This also is reasonable. After all, higher the volatility of house price, greater the market risk. In order to avoid the higher market risk, the lender will have to reduce the amount of annuity. (2) As the volatility of house price $\sigma_{h}$ remains unchanged, the annuity increases with the increase of the initial age; that is, the older applicant will get better annuity.

(c) Parameter $\rho_{h r}$, the correlation coefficient between Brown motions: Here, the parameter $\rho_{h r}$ denotes the correlation coefficient between the Brownian motion driving house price and that driving interest rate. (1) As the initial age is fixed, the annuity decreases with the increase of the correlation coefficient $\rho_{h r}$, as proved in Proposition 4. When the Brownian motion driving the house price and the Brownian motion driving the interest rate are completely negatively correlated $\left(\rho_{h r}=-1\right)$, the annuity reaches the maximum. If they are completely positively correlated $\left(\rho_{h r}=1\right)$, the annuity reaches the minimum. In addition, the annuity values under the different correlation coefficients are very close, which implies that the influence of the correlation coefficient $\rho_{h r}$ on the annuity is very weak. As an example, consider a male annuitant with initial age of 50. As the correlation coefficient increases from - 1 to 1 , the annuity reduces from $\$ 3.438$ to $\$ 3.068$, the average change rate of annuity w.r.t $\rho_{h r}$ is only 0.185. (2) Compared with the older applicants, the annuity of the younger applicant is more susceptible to the correlation coefficient. When the correlation coefficient $\rho_{h r}$ is fixed, the annuity increases with the increase of the initial age, that is, the older applicant will receive a larger annuity.

(d) Parameter $h_{0}$, the initial house price: (1) As the initial age is fixed, the annuity increases obviously with the increase of initial house price. The higher initial house price implies that the lender reaps greater benefits while selling the mortgaged property in the future. With the fair valuation, the lender will pay better annuity to the borrower. As is clear from Table 2 that these annuity values get closer to each other in the case of lower initial age, and while the initial age increases these annuity values gradually diverge. It means that the annuity for the older applicant is more affected by the initial house price than that of the younger applicant. (2) When the initial house price is fixed, the annuity increases with the increase of initial age; that is, the older applicant will be paid higher annuities every year as other factors, except for the initial age, are same. 
Table 3: Effect of interest rate on annuity values

\begin{tabular}{c|ccccccccccc}
\hline$x_{0}$ & 50 & 55 & 60 & 65 & 70 & 75 & 80 & 85 & 90 & 95 & 100 \\
\hline$r_{0}=0.01$ & 3.222 & 3.744 & 4.402 & 5.246 & 6.354 & 7.851 & 9.959 & 13.101 & 18.104 & 26.418 & 39.304 \\
$r_{0}=0.04$ & 3.193 & 3.708 & 4.356 & 5.187 & 6.276 & 7.745 & 9.809 & 12.877 & 17.757 & 25.876 & 38.505 \\
$r_{0}=0.07$ & 3.162 & 3.670 & 4.310 & 5.128 & 6.198 & 7.638 & 9.657 & 12.652 & 17.410 & 25.337 & 37.713 \\
$r_{0}=0.1$ & 3.131 & 3.633 & 4.262 & 5.067 & 6.118 & 7.529 & 9.503 & 12.426 & 17.064 & 24.801 & 36.931 \\
$r_{0}=0.13$ & 3.100 & 3.594 & 4.214 & 5.006 & 6.037 & 7.419 & 9.349 & 12.199 & 16.717 & 24.268 & 36.156 \\
\hline$\mu_{r}=0.02$ & 8.821 & 8.894 & 9.139 & 9.602 & 10.355 & 11.515 & 13.285 & 16.045 & 20.550 & 28.178 & 40.236 \\
$\mu_{r}=0.04$ & 5.346 & 5.766 & 6.319 & 7.056 & 8.052 & 9.428 & 11.396 & 14.354 & 19.083 & 26.987 & 39.351 \\
$\mu_{r}=0.06$ & 3.193 & 3.708 & 4.356 & 5.187 & 6.276 & 7.745 & 9.809 & 12.877 & 17.757 & 25.876 & 38.505 \\
$\mu_{r}=0.08$ & 1.899 & 2.384 & 3.011 & 3.831 & 4.917 & 6.393 & 8.477 & 11.588 & 16.557 & 24.839 & 37.695 \\
$\mu_{r}=0.1$ & 1.136 & 1.544 & 2.099 & 2.852 & 3.881 & 5.309 & 7.360 & 10.462 & 15.470 & 23.870 & 36.919 \\
\hline$\sigma_{r}=0.001$ & 3.226 & 3.741 & 4.390 & 5.222 & 6.311 & 7.779 & 9.843 & 12.910 & 17.788 & 25.903 & 38.526 \\
$\sigma_{r}=0.01$ & 3.193 & 3.708 & 4.356 & 5.187 & 6.276 & 7.745 & 9.809 & 12.877 & 17.757 & 25.876 & 38.505 \\
$\sigma_{r}=0.02$ & 3.187 & 3.701 & 4.349 & 5.179 & 6.267 & 7.734 & 9.797 & 12.865 & 17.744 & 25.863 & 38.492 \\
$\sigma_{r}=0.03$ & 3.215 & 3.727 & 4.373 & 5.201 & 6.287 & 7.753 & 9.814 & 12.879 & 17.754 & 25.867 & 38.491 \\
$\sigma_{r}=0.04$ & 3.276 & 3.786 & 4.430 & 5.256 & 6.339 & 7.801 & 9.858 & 12.918 & 17.786 & 25.888 & 38.502 \\
\hline$\alpha_{r}=0.05$ & 4.426 & 4.897 & 5.504 & 6.299 & 7.358 & 8.804 & 10.848 & 13.892 & 18.719 & 26.728 & 39.186 \\
$\alpha_{r}=0.15$ & 3.360 & 3.895 & 4.568 & 5.430 & 6.557 & 8.073 & 10.191 & 13.318 & 18.244 & 26.369 & 38.942 \\
$\alpha_{r}=0.35$ & 3.204 & 3.722 & 4.375 & 5.213 & 6.310 & 7.791 & 9.872 & 12.963 & 17.869 & 26.009 & 38.641 \\
$\alpha_{r}=0.55$ & 3.192 & 3.706 & 4.353 & 5.184 & 6.271 & 7.737 & 9.797 & 12.860 & 17.733 & 25.845 & 38.470 \\
$\alpha_{r}=0.75$ & 3.191 & 3.704 & 4.350 & 5.177 & 6.260 & 7.720 & 9.771 & 12.820 & 17.671 & 25.757 & 38.364 \\
\hline
\end{tabular}

\subsection{EFFECT OF INTEREST RATE ON ANNUITY VALUES}

This subsection provides the numerical analysis of how the interest rate influences the annuity $A$; again, we keep the other parametric values fixed as the standard case. Table 3 portrays the following analysis.

(a) Parameter $r_{0}$, the initial interest rate: Keeping the initial age fixed, the annuity decreases slightly with the increase of the initial interest rate $r_{0}$, that is, the higher the initial interest rate the lower the annuity payment. The initial interest rate $r_{0}$ has a less influence on the annuity of younger applicants than those of older applicants. In general, the initial interest rate $r_{0}$ weakly affects the annuity payments. When the initial interest rate is fixed, the annuity increases with the increase of the initial age.

(b) Parameter $\mu_{r}$, the average reversion level of interest rate: (1) Fixing the initial age, the annuity decreases with the increase of $\mu_{r}$. The average reversion level $\mu_{r}$ impacts more the annuity of younger borrowers than that of older borrowers. Generally, $\mu_{r}$ has a significant effect on the annuity. (2) With fixed average reversion level $\mu_{r}$, the annuity increases with the increase of initial age.

(c) Parameter $\sigma_{r}$, the volatility of interest rate: The volatility $\sigma_{r}$ of interest rate in Table 2 takes five values: $0.001,0.01,0.02,0.03,0.04$. The corresponding annuity values with different $\sigma_{r}$ almost coincides with each other under fixed initial male age. This indicates that the volatility of interest rate has weak effect on the annuity while the volatility of interest rate is at a low level. It is known from the 
original data that: while the initial age kept fixed, the annuity decreases slightly, with the increase of volatility rate $\sigma_{r}$ in case that $\sigma_{r} \leq \sigma_{h} \rho_{h r} \alpha_{r}=0.012$ (it is consistent with Proposition 6); and the annuity increases slightly with the increase of volatility rate $\sigma_{r}$ in case that $\sigma_{r} \geq \sigma_{h} \rho_{h r} \alpha_{r}=0.012$. Proposition 6 shows that the annuity amount decreases with increase of $\sigma_{r}$ in case of $\sigma_{r} \leq \sigma_{h} \rho_{h r} \alpha_{r}$. It implies that the valuation models can be used to determine the annuity payments as long as the volatility of interest rate $\sigma_{r}$ can be controlled by the quantity $\sigma_{h} \rho_{h r} \alpha_{r}$ (irrespective of the volatility rate).

(d) Parameter $\alpha_{r}$, the reversion speed of interest rate: As the initial age is fixed, the annuity decreases slowly with the increase of the reversion speed $\alpha_{r}$. While the reversion speed of interest rate is more than 0.75 , the annuity is basically stable. To further validate this view, the $\alpha_{r}$ is relaxed to 2.05. For the applicant with the initial age of 50 years old, the annuity is $\$ 3.192$ with $\alpha_{r}=0.85$, and the annuity is $\$ 3.200$ with $\alpha_{r}=2.05$. The change of annuity is very small. The $\alpha_{r}$ has a greater impact on the annuity of younger applicants than that of older applicants. While $\alpha_{r}$ remains unchanged, the annuity increases with the increase of the initial age, that is, the older applicants will receive larger annuity.

\subsection{EFFECT OF JOINT LIFETIME ON ANNUITY VALUES}

Table 4: Effect of joint lifetime on annuity values

\begin{tabular}{c|ccccccccccc}
\hline$x_{0}$ & 50 & 55 & 60 & 65 & 70 & 75 & 80 & 85 & 90 & 95 & 100 \\
\hline$m_{1}=69$ & 3.69 & 4.337 & 5.134 & 6.123 & 7.39 & 9.129 & 11.757 & 16.083 & 23.491 & 35.692 & 52.474 \\
$m_{1}=79$ & 3.401 & 3.976 & 4.701 & 5.626 & 6.832 & 8.45 & 10.743 & 14.287 & 20.304 & 30.641 & 45.906 \\
$m_{1}=89$ & 3.081 & 3.567 & 4.176 & 4.955 & 5.972 & 7.339 & 9.245 & 12.039 & 16.368 & 23.391 & 34.514 \\
$m_{1}=99$ & 2.658 & 3.05 & 3.534 & 4.142 & 4.918 & 5.929 & 7.269 & 9.089 & 11.637 & 15.412 & 21.528 \\
$m_{1}=109$ & 2.205 & 2.515 & 2.891 & 3.356 & 3.935 & 4.663 & 5.575 & 6.714 & 8.141 & 10.027 & 12.859 \\
\hline$\sigma_{1}=6$ & 3.138 & 3.66 & 4.342 & 5.259 & 6.529 & 8.339 & 11.001 & 15.037 & 21.627 & 33.609 & 51.684 \\
$\sigma_{1}=8$ & 3.176 & 3.699 & 4.37 & 5.249 & 6.426 & 8.045 & 10.359 & 13.846 & 19.529 & 29.443 & 45.100 \\
$\sigma_{1}=10$ & 3.193 & 3.708 & 4.356 & 5.186 & 6.275 & 7.742 & 9.804 & 12.868 & 17.741 & 25.843 & 38.443 \\
$\sigma_{1}=12$ & 3.191 & 3.691 & 4.312 & 5.095 & 6.106 & 7.451 & 9.316 & 12.041 & 16.239 & 22.884 & 32.886 \\
$\sigma_{1}=14$ & 3.175 & 3.658 & 4.251 & 4.991 & 5.935 & 7.179 & 8.882 & 11.327 & 14.974 & 20.478 & 28.458 \\
\hline$\alpha=-5$ & 3.223 & 3.736 & 4.378 & 5.195 & 6.260 & 7.690 & 9.689 & 12.640 & 17.335 & 25.322 & 38.180 \\
$\alpha=-4$ & 3.205 & 3.720 & 4.365 & 5.190 & 6.267 & 7.717 & 9.751 & 12.768 & 17.573 & 25.645 & 38.376 \\
$\alpha=-3$ & 3.185 & 3.700 & 4.350 & 5.186 & 6.283 & 7.765 & 9.851 & 12.953 & 17.879 & 26.021 & 38.581 \\
$\alpha=-2$ & 3.160 & 3.677 & 4.334 & 5.184 & 6.310 & 7.842 & 10.006 & 13.224 & 18.286 & 26.464 & 38.797 \\
$\alpha=-1$ & 3.134 & 3.652 & 4.316 & 5.185 & 6.350 & 7.954 & 10.236 & 13.615 & 18.832 & 26.987 & 39.023 \\
\hline
\end{tabular}

In this subsection we discuss the impact on annuity value by joint lifetime, including the parameters $m_{1}, \sigma_{1}$ and $\alpha$. Table 4 shows that:

(a) Parameter $m_{1}$, the modal value of male lifetime: Since the parameters $m_{1}$ and $m_{2}$ in the respective Gompertz distributions have the same function, we consider only the parameter $m_{1}$ for illustration. The reader can draw the corresponding 
analysis for $m_{2}$. Part 1 of Table 4 shows that: (1) As the initial age is fixed, the annuity decreases with the increase of $m_{1}$. The annuity for the older applicants is more sensitive to the change of $m_{1}$ than that for the younger applicants. (2) As $m_{1}$ is fixed, the annuity increases with the increase of the initial age, that is, older the applicant is, higher the annuity he will receive. (3) Smaller the parameter $m_{1}$ becomes, greater the impact on annuity the parameter $m_{1}$ will exert.

(b) Parameter $\sigma_{1}$, the dispersion coefficient of male lifetime: The parameter $\sigma_{1}$ shares the same function with $\sigma_{2}$. We shall treat only the parameter $\sigma_{1}$ for illustration purpose. With fixed initial age, the annuity shows two different trends with the change of $\sigma_{1}$ : (1) When the initial age is at a lower level (say, $x_{0}=50,55,60$ ), the annuity increases first and then decreases with the increase of $\sigma_{1}$. bf (2) When the initial age is at a higher level (say, $x_{0}=70,75, \ldots, 100$ ), the annuity decreases with the increase of $\sigma_{1}$. The annuity of an older applicant is more strongly affected by $\sigma_{1}$. As $\sigma_{1}$ remains unchanged, the annuity increases with the increase of initial age $x_{0}$.

(c) Parameter $\alpha$, the dependence between male and female lifetime: As the initial age remains fixed, the change of annuity shows three different trends: (1) when the initial age is at a lower level (say $x_{0}=50,55,60$ ), the annuity decreases with the increase of $\alpha ;(2)$ when the initial age is at the middle level (say $x_{0}=65$ ), the annuity decreases first and then increases with the increase of $\alpha ;(3)$ as the initial age is at a higher level ( say $x_{0}=70,75, \ldots, 100$ ), the annuity increases with the increase of $\alpha$. (4) In general, the impact of $\alpha$ on older applicants' annuities is significantly stronger than that for young applicants' annuities. As $\alpha$ is fixed, the annuity increases with the increase of the applicant age, that is, the older the applicants are, the greater annuity they will be paid.

\subsection{EFFECT OF INITIAL AGE ON ANNUITY VALUES}

Table 5: Effect of joint lifetime on annuity values

\begin{tabular}{c|cccccccccc}
\hline$\left(x_{0}, y_{0}\right)$ & $(55,50)$ & $(60,55)$ & $(65,60)$ & $(70,65)$ & $(75,70)$ & $(80,75)$ & $(85,80)$ & $(90,85)$ & $(95,90)$ & $(100,95)$ \\
\hline Annuity & 3.490 & 4.084 & 4.837 & 5.811 & 7.099 & 8.863 & 11.410 & 15.374 & 22.032 & 33.089 \\
\hline$\left(x_{0}, y_{0}\right)$ & $(50,55)$ & $(55,60)$ & $(60,65)$ & $(65,70)$ & $(70,75)$ & $(75,80)$ & $(80,85)$ & $(85,90)$ & $(90,95)$ & $(95,100)$ \\
\hline Annuity & 3.590 & 4.206 & 4.995 & 6.028 & 7.418 & 9.358 & 12.184 & 16.502 & 23.417 & 34.329 \\
\hline$\left(x_{0}, y_{0}\right)$ & $(60,50)$ & $(65,55)$ & $(70,60)$ & $(75,65)$ & $(80,70)$ & $(85,75)$ & $(90,80)$ & $(95,85)$ & $(100,90)$ & \\
\hline Annuity & 3.653 & 4.293 & 5.103 & 6.142 & 7.505 & 9.369 & 12.110 & 16.572 & 24.357 \\
\hline$\left(x_{0}, y_{0}\right)$ & $(50,60)$ & $(55,65)$ & $(60,70)$ & $(65,75)$ & $(70,80)$ & $(75,85)$ & $(80,90)$ & $(85,95)$ & $(90,100)$ \\
\hline Annuity & 3.846 & 4.537 & 5.430 & 6.606 & 8.193 & 10.399 & 13.587 & 18.530 & 26.675 \\
\hline$\left(x_{0}, y_{0}\right)$ & $(65,50)$ & $(70,55)$ & $(75,60)$ & $(80,65)$ & $(85,70)$ & $(90,75)$ & $(95,80)$ & $(100,85)$ & & \\
\hline Annuity & 3.811 & 4.492 & 5.342 & 6.417 & 7.816 & 9.756 & 12.723 & 17.726 & & \\
\hline$\left(x_{0}, y_{0}\right)$ & $(50,65)$ & $(55,70)$ & $(60,75)$ & $(65,80)$ & $(70,85)$ & $(75,90)$ & $(80,95)$ & $(85,100)$ & & \\
\hline Annuity & 4.086 & 4.852 & 5.837 & 7.121 & 8.816 & 11.119 & 14.521 & 20.137 & & \\
\hline
\end{tabular}




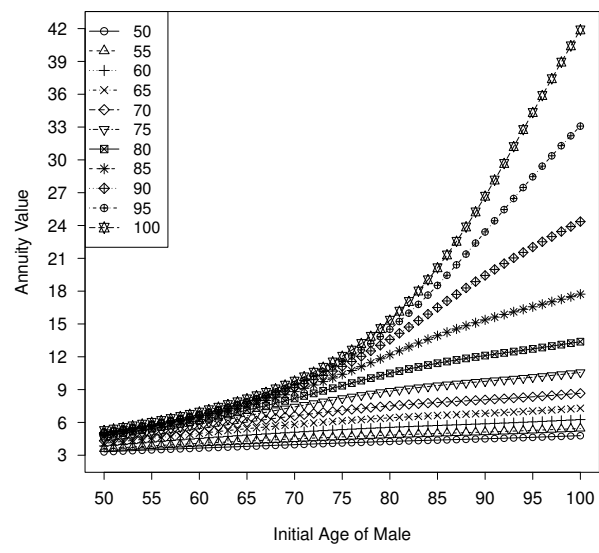

(a)

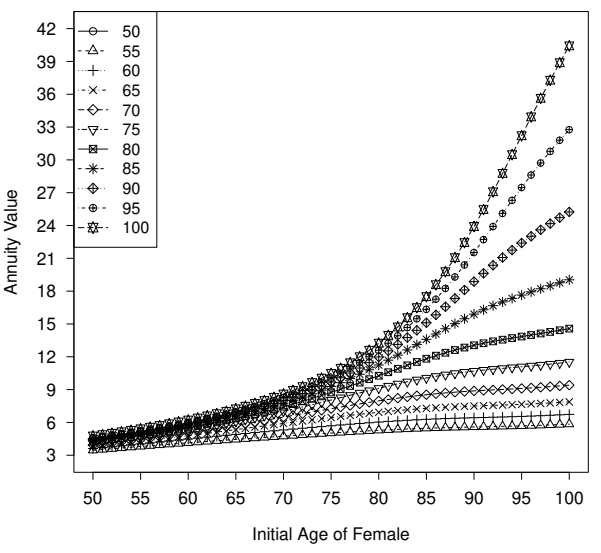

(b)

Figure 1: Effect of the initial age on annuity values with dependent assumption

In order to evaluate the effect of the initial ages $x_{0}, y_{0}$ on the annuity, Figure 1 presents the scatter plot of the joint and $\gamma$ annuity. Figure 1(a) shows that: Keeping the initial age $y_{0}\left(y_{0}=50,55, \ldots, 100\right)$ of the female annuitant fixed, the annuity value increases with the increase of the male applicant's initial age $x_{0}$, (the initial age of male applicant is between 50 and 100). The larger the initial age of female is, the stronger effect it will exert on the annuity amount.

Figure 1(b) reveals that: When the initial age $x_{0}\left(x_{0}=50,55, \ldots, 100\right)$ of male applicant is fixed, the annuity amount increase with the increase of the female's initial age $y_{0}$, (the initial age of female is taken to be between 50 and 100). The larger the initial age of male is, the stronger influence it will produce on the the annuity value.

Comparing Figure 1(a) with Figure 1(b), it is not difficult to find that: the annuity value is approximately symmetrical, though not completely symmetrical in the initial $x_{0}$ and $y_{0}$. When the age difference between the male and female annuitants is the same, different influences are made on the annuity value in the case with the initial age $y_{0}$ of female is greater than that of male and vice versa. Especially, when $y_{0}-x_{0}=d$ ( $d$ is a positive constant) the annuity value is greater than that when $x_{0}-y_{0}=d$. To validate this claim, we present the annuity values with the age difference of 5,10 and 15 years (see Table 5). 


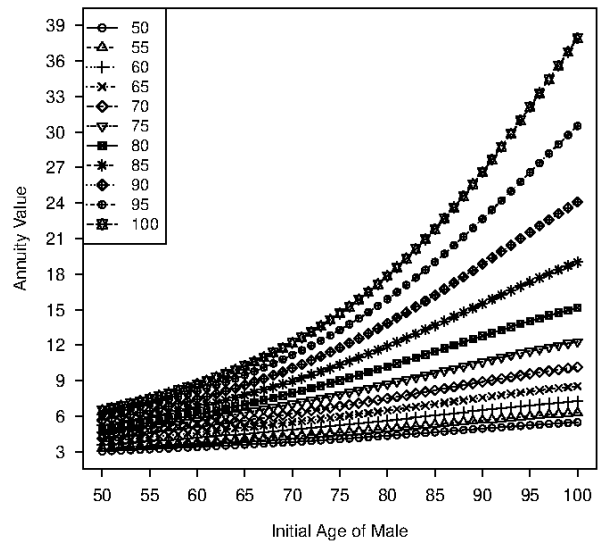

(a)

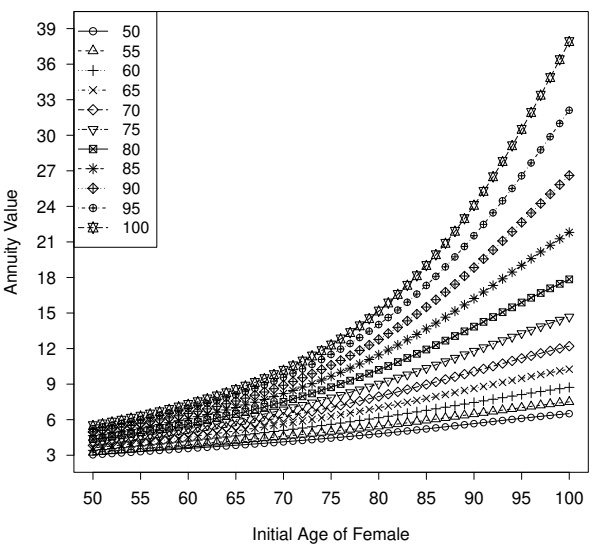

(b)

Figure 2: Effect of the initial age on annuity values with independent assumption.

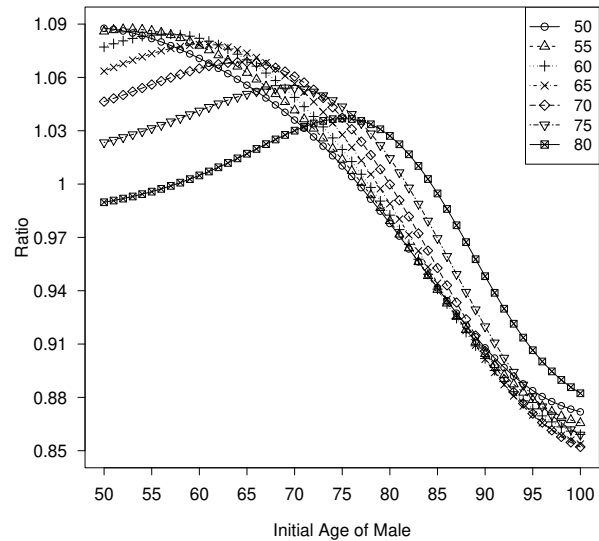

(a)

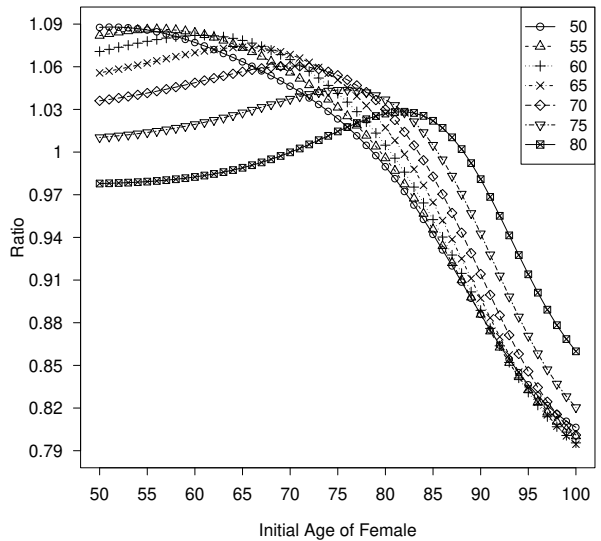

(b)

Figure 3: Effect of dependence on annuity values.

\subsection{EFFECT OF DEPENDENCE ON ANNUITY VALUES}

In order to evaluate the effect of the dependence of joint-lifetime on the annuity, we further compute the annuity value with the assumption of independence between the husband's lifetime and the wife's lifetime. Also, we assume that the husband is two 
years older than his wife (i.e., $x_{0}=y_{0}+2$ ), and the parameters of joint lifetime model take the following values: $m_{1}=86.38, m_{2}=92.17, \sigma_{1}=9.83, \sigma_{2}=8.11$ (see Frees et al., 1996). In Figure 2(a) (respectively, Figure 2(b)), the initial age of female (respectively, male) is fixed as 50, 55, ...,100. With these assumptions, Figure 2(a) (respectively, Figure 2(b)) shows how the annuity values vary with the initial age of male (respectively, female). Comparing Figure 2(a) (respectively, Figure 2(b)) with Figure 1(a) (respecgtively, Figure 1(b)), it is easy to note that the annuity values with the dependence assumption are not same with those with independence assumption. Figure 3(a) and 3(b) present the multiple scatter plot of the ratio of dependent to independent. Ratios that are greater than one indicate that annuity values calculated with dependence assumption of lives are larger than those calculated with independence assumption. Annuity values in average increase approximately $4.5 \%$, and the greatest increment in annuity value approaches $9 \%$.

\subsection{EFFECT OF OTHER PARAMETERS ON ANNUITY VALUES}

Table 6: Effect of other parameters on annuity values

\begin{tabular}{c|ccccccccccc}
\hline$x_{0}$ & 50 & 55 & 60 & 65 & 70 & 75 & 80 & 85 & 90 & 95 & 100 \\
\hline$t_{0}=0$ & 3.193 & 3.708 & 4.356 & 5.187 & 6.276 & 7.745 & 9.809 & 12.877 & 17.757 & 25.876 & 38.505 \\
$t_{0}=3$ & 3.004 & 3.489 & 4.099 & 4.881 & 5.907 & 7.290 & 9.236 & 12.133 & 16.752 & 24.475 & 36.573 \\
$t_{0}=6$ & 2.827 & 3.283 & 3.857 & 4.593 & 5.558 & 6.860 & 8.692 & 11.420 & 15.772 & 23.057 & 34.487 \\
$t_{0}=9$ & 2.660 & 3.089 & 3.629 & 4.322 & 5.230 & 6.455 & 8.179 & 10.746 & 14.843 & 21.702 & 32.466 \\
$t_{0}=12$ & 2.503 & 2.907 & 3.415 & 4.067 & 4.922 & 6.074 & 7.696 & 10.112 & 13.967 & 20.422 & 30.553 \\
\hline$\gamma=1 / 2$ & 3.193 & 3.708 & 4.356 & 5.187 & 6.276 & .745 & 9.809 & 12.877 & 17.757 & 25.876 & 38.505 \\
$\gamma=2 / 3$ & 3.129 & 3.615 & 4.221 & 4.990 & 5.987 & 7.314 & 9.157 & 11.868 & 16.162 & 23.349 & 34.755 \\
$\gamma=3 / 4$ & 3.099 & 3.571 & 4.157 & 4.897 & 5.851 & 7.116 & 8.862 & 11.421 & 15.468 & 22.262 & 33.141 \\
$\gamma=4 / 5$ & 3.080 & 3.545 & 4.119 & 4.843 & 5.773 & 7.002 & 8.694 & 11.168 & 15.079 & 21.657 & 32.242 \\
$\gamma=1$ & 3.010 & 3.444 & 3.975 & 4.638 & 5.481 & 6.582 & 8.082 & 10.260 & 13.701 & 19.534 & 29.088 \\
\hline
\end{tabular}

(a) Parameter $t_{0}$, the delay time in selling the pledged house: Table 6 shows that: As the initial age is fixed, the annuity slowly decreases with the increase of the delay time of selling the pledged house, that is, the applicant will receive less annuities, while the delay time of selling house becomes longer. The impact of delay time on the annuity is complex. While the other parameters in the valuation model change, the annuity may also increase with the increase of delay time. The delay time more affects the annuity of the older borrowers than those of the younger borrowers. However, the delay time has a weak impact on the annuity.

While the delay time of selling house remains unchanged, the annuity increases with the increase of the initial age. Facing the different delay time, the applicant with different initial age may get the approximately same annuity. For example, with no delay, the applicant with 53 years old obtains annuity amount $\$ 3.488$ every year; and 


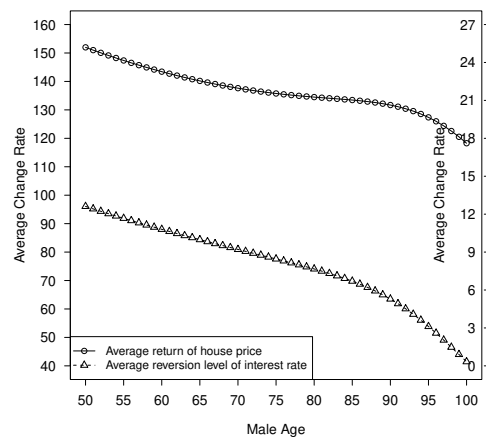

(a)

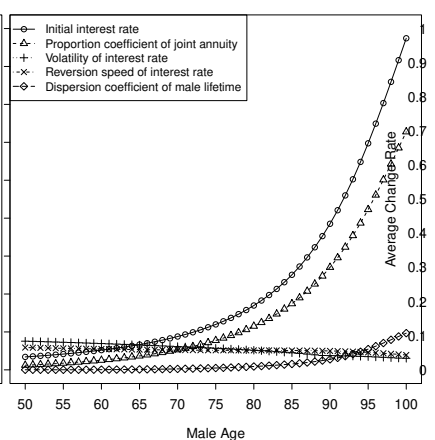

(b)

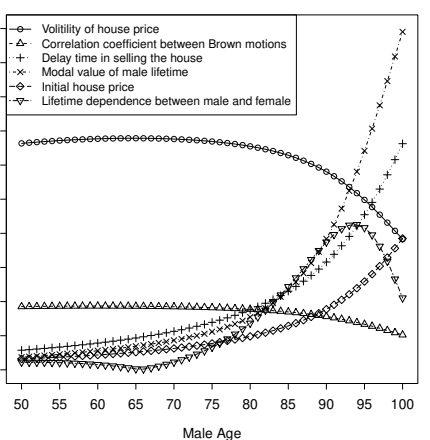

(c)

Figure 4: Average change rate for all parameters.

with three years delay, the applicant with 55 years old gets annuity amount $\$ 3.489$. These two annuity amounts are almost same.

(b) Parameter $\gamma$, the proportion coefficient of joint annuity: In order to evaluate the effect of the $\gamma$ on the annuity, Table 6 presents the joint and $\gamma$ annuity values. It shows that: As the initial age is fixed, the annuity payment decreases slowly with the increase of $\gamma$. The effect of $\gamma$ on the annuity for older applicants is stronger than that of younger applicants. As $\gamma$ remains unchanged, the annuity increases with the increase of initial age.

\subsection{COMPARISON OF ALL PARAMETERS}

The average return rate of house price $\mu_{h}$ exerts a dominating impact on the annuity. The rates of $\mu_{h}$ are between 118 and 152, (see Figure 4(a)), much much larger than that of other parameters. The $\mu_{r}$ has the second strongest impact on the annuity, and the average change rate of $\mu_{r}$ is between 41 and 97 (see Figure 4(a)), followed by $r_{0}, \gamma, \sigma_{r}, \alpha_{r}$ and $\sigma_{1}$ (see Figure $4(\mathrm{~b})$ ). The average change rates of other parameters are between 0 and 1 (see Figure 4(c)), which implies that the other parameters have very weak influence on the annuity value. The parameters $\mu_{h}, \mu_{r}, \sigma_{r}$ and $\alpha_{r}$ affect the annuity of younger borrower more than that of older borrower. The parameters $r_{0}, \gamma, \sigma, t_{0}, m_{1}$ and $h_{0}$ have much greater influence on the annuity of an older applicant than that of an young applicant. The parameters $\sigma_{h}$ and $\rho_{h r}$ exert almost same effect on the annuity of younger annuitant with that of older annuitant in case that the initial age of male is between 50 and 100 . 


\section{CONCLUSION}

Based on the valuation principle of balance between expected gain and expected payment, this paper builds a valuation model for reverse mortgage applied to a coupleannuitants. We obtain the analytic valuation formula for the lump sum, joint annuity, increasing (decreasing) annuity, level annuity of reverse mortgage, and derive the valuation equation that the variable payment annuities satisfy. Then, we discuss the monotonicity of the lump sum, annuity, and annuity payment factors with respect to the parameters associated with the home price and the interest rate model. Finally, we present a sensitivity analysis for the joint and $\gamma$ annuity to the parameters associated with the home price, interest rate and mortality model. Corresponding to the average change rate, we compare the impact of the said parameters on the joint and $\gamma$ annuity. The numerical results show that the average return of home price $\mu_{h}$ exerts a dominating influence on the joint and $\gamma$ annuity, followed by the mean reversion level of interest rate $\mu_{r}$. Next to $\mu_{h}$ and $\mu_{r}$, the initial interest rate $r_{0}$, the proportion coefficient of joint annuity $\gamma$, the volatility of interest rate $\sigma_{r}$, the reversion speed of interest rate $\alpha_{r}$ and the dispersion coefficient of male lifetime $\sigma_{1}$ also impact on the joint annuity value. The rest parameters $\sigma_{h}, \rho_{h r}, t_{0}, m_{1}, h_{0}$ and $\alpha$ have very weak influence on the annuity value. Meanwhile, the initial age of male $x_{0}$ and that of female $y_{0}$ produce asymmetrical effect on the joint and $\gamma$ annuity. Remarkably, the dependence of joint-lifetime significantly affect the joint annuity value. Annuity values in average increase approximately $4.5 \%$, and the greatest increment of annuity value approaches $9 \%$ in case that the initial age of male and female are both less than 80 .

However, it should be noted that the average change rates depend on the ranges of the parameters. Once the ranges of parameters change, it may change the evaluation results for the parameters. Thus, the appropriate range should be chosen in order to make objective evaluations of the parameters' effects. Moreover, the model selection of the house price, interest rate and lifetime will directly affect the final valuation results. Therefore, it is suggested to collect the data of house price, interest rate and population in the area that the reverse mortgage product covers, and model the special house price, interest rate and lifetime model based on the collected historical data before employing the valuation model. This will be one of our future research works. It will offer reasonable valuation of reverse mortgage, and help the lender of reverse mortgage to better manage and control risk.

\section{APPENDIX A: DERIVATION OF PROPOSITION 1}

This appendix gives the derivations of Proposition 1. 
Proof. It is easy to get that $Y(t)$ follows the normal distribution with the mean 0 and variance

$$
\sigma_{y}^{2}(t)=\frac{\sigma_{r}^{2}}{\alpha_{r}^{2}} t+\frac{\sigma_{r}^{2}}{2 \alpha_{r}^{3}}\left[1-\left(2-e^{-\alpha_{r} t}\right)^{2}\right] .
$$

Noting that $\operatorname{Cov}\left(d W_{h}(t), d W_{r}(t)\right)=\rho_{h r} d t$, we can obtain the covariance between $W_{h}(t)$ and $Y(t)$, that is

$$
\operatorname{Cov}\left(W_{h}(t), Y(t)\right)=\sigma_{r} \rho_{h r} \frac{1}{\alpha_{r}}\left(t+\frac{1}{\alpha_{r}} e^{-\alpha_{r} t}-\frac{1}{\alpha_{r}}\right) .
$$

Thus the correlation coefficient between $W_{h}(t)$ and $Y(t)$ denoted by $\rho(t)$ is

$$
\rho(t)=\frac{\sigma_{r} \rho_{h r}}{\alpha_{r} \sigma_{y}(t) \sqrt{t}}\left(t+\frac{1}{\alpha_{r}} e^{-\alpha_{r} t}-\frac{1}{\alpha_{r}}\right) .
$$

Since the joint distribution of $\left(W_{h}(t), Y(t)\right)$ follows the two dimension normal distribution with the correlation coefficient $\rho(t)$ given by Eq. (A.2), we have with Eq. (A.1)

$$
E\left\{\exp \left[\sigma_{h} W_{h}(t)-Y(t)\right]\right\}=\int_{-\infty}^{+\infty} \int_{-\infty}^{+\infty} \exp \left(\sigma_{h} x-y\right) f(x, y) d x d y
$$

where

$$
f(x, y)=\frac{1}{2 \pi \sigma_{y}(t) \sqrt{t\left(1-\rho^{2}(t)\right)}} \exp \left\{-\frac{1}{2\left(1-\rho^{2}(t)\right)} S_{x y}\right\},
$$

and

$$
S_{x y}=\left(\frac{x}{\sqrt{t}}\right)^{2}-2 \rho(t) \frac{x}{\sqrt{t}} \frac{y}{\sigma_{y}(t)}+\left(\frac{y}{\sigma_{y}(t)}\right)^{2} .
$$

Making the transform $u=\frac{x}{\sqrt{t}}$ and $v=y-\rho(t) \sigma_{y}(t) u$, then we obtain

$$
\begin{aligned}
E\left\{\exp \left[\sigma_{h} W_{h}(t)-Y(t)\right]\right\} & =\int_{-\infty}^{+\infty} \int_{-\infty}^{+\infty} \exp \left\{\left[\sigma_{h} \sqrt{t}-\rho(t) \sigma_{y}(t)\right] u-v\right\} g(u, v) d u d v \\
& =\exp \left[\frac{1}{2} \sigma_{h}^{2} t-\rho(t) \sigma_{y}(t) \sigma_{h} \sqrt{t}+\frac{1}{2} \sigma_{y}^{2}(t)\right],
\end{aligned}
$$

where

$$
g(u, v)=\frac{1}{2 \pi \sigma_{y}(t) \sqrt{1-\rho^{2}(t)}} \exp \left\{-\frac{1}{2}\left[u^{2}+\frac{v^{2}}{\sigma_{y}^{2}(t)\left(1-\rho^{2}(t)\right)}\right]\right\} .
$$

Noting $\{N(t), t \geq 0\}$ and $\left\{J_{i}, i \geq 1\right\}$ are independent, and $J_{i}$ follows the normal distribution with mean $\mu_{J}$ and variance $\sigma_{J}^{2}$, we obtain

$$
E\left[e^{\sum_{i=1}^{N(t)} J_{i}}\right]=\exp \left(k_{h} \lambda_{h} t\right)
$$

where $k_{h}:=\exp \left(\mu_{J}+\frac{1}{2} \sigma_{J}^{2}\right)-1$ as defined in the interest rate model. 
Let

$$
\begin{aligned}
m_{1} & :=\int_{0}^{t} \mu_{h}(s) d s-\left(\frac{1}{2} \sigma_{h}^{2}+\lambda_{h} k_{h}\right) t, \\
m_{2} & :=\mu_{r} t+\frac{1}{\alpha_{r}}\left(\mu_{r}-r_{0}\right)\left(e^{-\alpha_{r} t}-1\right) .
\end{aligned}
$$

It is easy to get

$$
\begin{aligned}
h(t) & =h_{0} \exp \left[m_{1}+\sigma_{h} W_{h}(t)+\sum_{i=1}^{N(t)} J_{i}\right], \\
\int_{0}^{t} r(u) d u & =m_{2}+Y(t) .
\end{aligned}
$$

Noting that $\sigma_{h} W_{h}(t)-Y(t)$ is independent of $\sum_{i=1}^{N(t)} J_{i}$, with Eq. (A.3)-(A.6), we have

$$
\begin{aligned}
E[h(t) d(t)] & =h_{0} e^{m_{1}-m_{2}} E\left[e^{\sigma_{h} W_{h}(t)-Y(t)}\right] E\left[e^{\sum_{i=1}^{N(t)} J_{i}}\right] \\
& =G(t) D(t)
\end{aligned}
$$

where $G(t)$ and $D(t)$ is respectively defined by Eq. (14) and (15). We obtain the Proposition 1.

\section{ACKNOWLEDGMENTS}

Research of this author was supported by the National Science Foundation of China (Grant No. 71401124), Foundation of National Statistical Science Research in China (Grant No. 2015LZ03), and Science and Technology Development Foundation of College in Tianjin (Grant No. 20131004).

\section{REFERENCES}

[1] Bardhan, A., Karapandza, R., Urosevic, B., (2006): Valuing mortgage insurance contracts in emerging market economics; Journal of Real Estate Finance and Economics, 32 (1), 9-20.

[2] Black, F., Karasinski, P. (1991): Bond and option pricing when short rates are lognormal; Financial Analysts Journal, 47, 52-59.

[3] Brigo, D., Mercurio, F. (2006): Interest Rate Models-Theory and Practice: With Smile, Inflation and Credit; Springer Berlin.

[4] Carrière, J. F. (1994): An investigation of the gompertz law of mortality; Actuarial Research Clearing House, 2, 1-34. 
[5] Chen, M.C., Chang, C.C., Lin, S.K., Shyu, S.D., (2010a): Estimation of housing price jump risks and their impact on the valuation of mortgage insurance contacts; Journal of Risk and Insurance, 77 (2), 399-422.

[6] Chen, H., Cox, S.H., Wang, S.S., (2010b): Is the home equity conversion mortgage in the United States sustainable? evidence from pricing mortgage insurance premiums and non-recourse provisions using the conditional Esscher transform; Insurance: Mathematics and Economics, 46 (2), 371-384.

[7] Chinloy, P., Cho, M., Megbolugbe, I.F., (1997): Appraisals, transaction incentives, and smoothing; Journal of Real Estate Finance and Economics, 14 (1), 89-112.

[8] Cox, J.C., Ingersoll, J.E., and Ross, S.A. (1985): A theory of the term structure of interest rates; Econometrica, 53, 385-407.

[9] Diventi, T. R., Herzog, T. N. (1990): Modeling home equity conversion mortgages; Actuarial research clearing house, 2, 1-24.

[10] Dothan, L.U. (1978): On the term structure of interest rates; Journal of Financial Economics 6, 59-69.

[11] Frees, E. W., J. Carrière, and E. Valdez (1996): Annuity Valuation With Dependent Mortality; Journal of Risk and Insurance 63 (2), 229-261.

[12] Gompertz, B. (1825): On the nature of the function expressive of the law of human mortality, and on a new mode of determining the value of life contingencies; Philosophical Transactions of the Royal Society of London 115, 513C583.

[13] Heligman, L., Pollard, J. H. (1980): The age pattern of mortality; Journal of the institute of actuaries 107, 49-75.

[14] Huang, H.C., Wang, C.W., Miao, Y.C., (2011): Securitization of crossover risk in reverse mortgages; Geneva Papers on Risk and Insurance-Issues and Practice, 36 (4), 622-647.

[15] Hull, J., White, A. (1990): Pricing Interest Rate Derivative Securities; The Review of Financial Studies, 3, 573-592.

[16] Lee, R.D., and Carter, L. R. (1992): Modeling and forecasting U.S. mortality; Journal of the American Statistical Association, 87, 659-675.

[17] Lee, Y. T., Wang, Ch. W., and Huang, H. C. (2012): On the valuation of reverse mortgages with regular tenure payments; Insurance: Mathematics and Economics, 51, 430-441.

[18] Li, J.S.H., Hardy, M.R., Tan, K.S. (2010): On pricing and hedging the nonegative equity guarantee in equity release mechanisms; The Journal of Risk and Insurance, 77 (2), 499-522. 
[19] Ma, L., Zhang, J., Kannan, D. (2017): Fair Pricing Of Reverse Mortgage Without Redemption Right; Dynamic Systems and Applications, 26, 473-498.

[20] Makeham, W. M. (1860): On the law of mortality and the construction of annuity tables; Journal of the institute of actuaries, 8, 301-310.

[21] Makeham, W. M. (1867): On the law of mortality; Journal of the institute of actuaries, 13, 325-358.

[22] Mercurio, F., Moraleda, J.M. (2000): An analytically tractable interest rate model with humped volatility; European Journal of Operational Research, 120, 205-214.

[23] Mitchell, O. S., Piggott, J. (2004): Unlocking housing equity in Japan; Journal of the Japanese and International Economies, 18, 466-505.

[24] Mizrach, B., (2012): Jump and co-jump risk in subprime home equity derivatives; Journal of Portfolio Management, 38(2), 136-146.

[25] Nothaft, F.E., Gao, A.H., Wang, G.H.K. (1995): The stochastic behavior of the Freddie Mac/Fannie Mae conventional mortgage home price index; American Real Estate and Urban Economics Association Annual Meeting, San Francisco.

[26] Norberg R. (2004): Vasicek beyond the normal; Mathematical Finance, 14(4), 585-604.

[27] Ohgaki, H. (2003), Economic implication and possible structure for reverse mortgage in Japan; Rits University, 1-14.

[28] Szymanoski, E. J., (1994): Risk and the home equity conversion Mortgage; Journal of the American Real Estate and Urban Economics Association, 22(2), 347366.

[29] Tsay, J. T., Lin, C. C., Prather, L. J., Richard J. Buttimer Jr., (2014): An approximation approach for valuing reverse mortgages; Journal of Housing Economics, 25, 39-52.

[30] Tse, Y. K., (1995): Modelling reverse mortgages; Asia Pacific Journal of Management, 12(2), 79-95.

[31] Vasicek, O. (1977): An equilibrium characterization of the term structure; Journal of Financial Economics, 5, 177-188.

[32] Wang, L., Valdez, E.A., Piggott, J., (2008): Securitization of longevity risk in reverse mortgages; North American Actuarial Journal, 12(4), 345-371.

[33] Weibull W. A. (1951): Statistical distribution function of wide applicability; Journal of Applied Mechanics, 18, 293-297. 
